\title{
1 Unravelling ant-symbiont network topology across Europe
}

2 Thomas Parmentier ${ }^{1,2^{*}}$, Frederik de Laender ${ }^{2, \dagger}$, Dries Bonte ${ }^{1, \dagger}$

$4{ }^{1}$ Terrestrial Ecology Unit (TEREC), Department of Biology, Ghent University, K.L.

5 Ledeganckstraat 35, B-9000 Gent, Belgium

2 Research Unit of Environmental and Evolutionary Biology, Namur Institute of 9 Complex Systems, and Institute of Life, Earth, and the Environment, University of 10 Namur, Rue de Bruxelles 61, 5000 Namur, Belgium

${ }^{*}$ Correspondence:

${ }^{\dagger}$ These authors contributed equally

21

22

Key words: ant guests, commensalism, ecological network, Formicidae, host-parasite network, host switching, inquiline, microcosm, mutualism, parasite species richness, 


\section{ABSTRACT}

27

28

29
Long-term associations between different species are key drivers in community composition in all ecosystems. Understanding the ecological and evolutionary drivers of these symbiotic associations is challenging because of the diversity of species and interaction types hosted in natural ecological networks. Here, we compiled the most complete database on natural ant-symbiont networks in Europe to identify the drivers of bipartite network topology. These ant-symbiont networks host an unrivalled diversity of symbiotic associations across the entire mutualism-antagonism continuum, of which the most diverse types of symbionts are (1) trophobionts: mutualistic aphids and scale insects (2) myrmecophiles: commensalistic and parasitic arthropods, and (3) social parasites: parasitic ant species. These diverse antsymbiont networks provide a unique opportunity to tease apart ecological and evolutionary drivers. To do so, we dissected network topology and asked what determines host specificity and which host factors drive symbiont species richness and facilitate host switching for the different types of symbionts.

We found an unexpectedly high number of 701 obligate symbionts associated with European ants. Symbiont type explained host specificity and the average relatedness of the targeted host species. Social parasites were associated with few, but phylogenetically highly related hosts, whereas trophobionts and myrmecophiles interacted with a higher number of hosts across a wider taxonomic distribution. Colony size, host range and habitat type predicted total symbiont richness, where ants hosts with larger colony size or larger distribution range contained more symbiont species. However, we found that different sets of host factors affected diversity in the different types of symbionts. Ecological factors, such as colony size, host range and niche width predominantly drive myrmecophile species richness, whereas evolutionary factors, such as host phylogeny and biogeography, mainly determine richness of mutualistic trophobionts and social parasites. Lastly, we found that hosts with a common 
53 biogeographic history support a more similar community of symbionts. Phylogenetic related

54 hosts also shared more trophobionts and social parasites, but not myrmecophiles.

55 Taken together, these results suggest that ecological and evolutionary processes drive host

56 specificity and symbiont richness in large-scale ant-symbiont networks, but these drivers may

57 shift in importance depending on the type of symbiosis. Our findings highlight the potential of

58 well-characterized bipartite networks composed of different types of symbioses to identify

59 candidate processes driving community composition.

60 


\section{CONTENTS}

62

63

64

65

66

67

68

69

III. RESULTS.

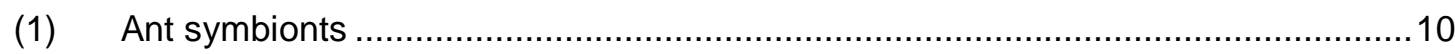

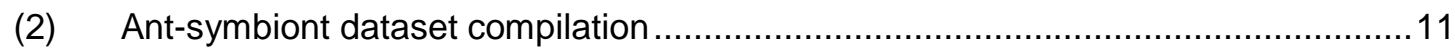

(3) Host specificity in different symbiont types ...................................................... 12

(4) Predictors of symbiont diversity in European ants ........................................... 13

(5) Predictors of symbiont sharing in European ants .............................................. 15 18

(1) Ant-symbiont networks display a diversity of species interactions..........................18

(2) Host specificity in different symbiont types .................................................. 19

(3) Predictors of symbiont diversity in European ants ............................................ 19

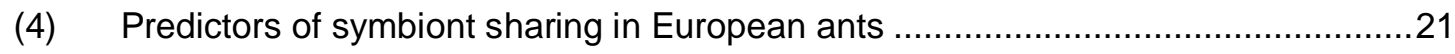

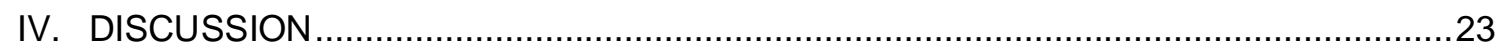

(1) Characterization of the European ant-symbiont network ..................................23

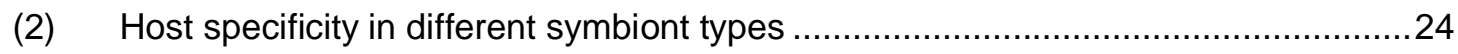

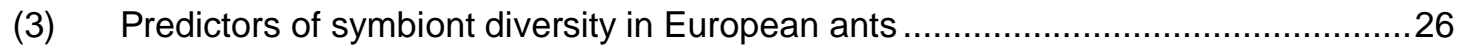

(4) Predictors of symbiont sharing in European ants ...........................................2

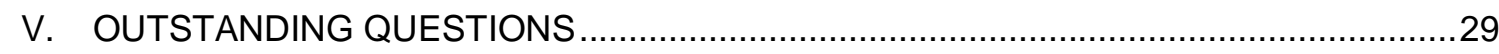

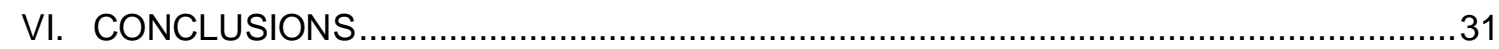

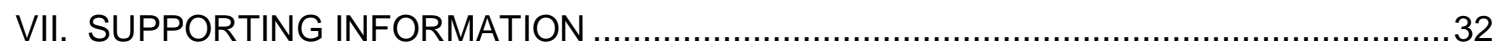

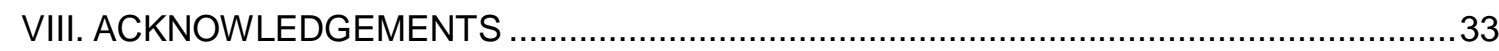

87 


\section{I. INTRODUCTION}

89

90

91

92

93

94

95

96

97

98

100

101

102

103

104

105

106

107

108

109

110

111

112

113

Long-term associations between different species, known as symbioses, are crucial components of community assembly in all ecosystems. These intricate associations display a high diversity, ranging from mutually beneficial partnerships to parasitic interactions, where one species exploits another (Paracer \& Ahmadjian, 2000). Interactions among species are central to ecological and evolutionary dynamics in assemblages of species that belong to different guilds and trophic levels. They are as such essential elements of the entangled bank, Darwin's metaphor for the complexity and connectedness of natural systems (Darwin, 1859), and give rise to important stabilising feedbacks that eventually maintain diversity and ecosystem functioning (Thrall et al., 2007; Bastolla et al., 2009). To date, these insights are merely derived from theory and empiricism focusing on either antagonistic competition and predator-prey interactions (e.g. Hairston, Smith, \& Slobodkin, 1960; Pimm, 1979; Tilman, 1982) or more recently mutualistic interactions (Bascompte, Jordano, \& Olesen, 2006; Bascompte \& Jordano, 2007).

Communities contain a wide variety of interactions, rendering the ecological network very complex (Newman, 2003). One important feature of complex systems is the presence of emergent properties that result from interactions among the specific components of the system (Solé \& Bascompte, 2006). Typically, the emergent properties result from the complex interaction between the different network components across time and space and are difficult to predict from the specific (isolated) pairwise interactions (Vázquez, Chacoff, \& Cagnolo, 2009). Generally speaking, modular networks that are characterised by a high degree distribution and connectance tend to be more robust to species loss, and are less affected by disturbance (Solé \& Bascompte, 2006; Olesen et al., 2007). While theoretical progress has been made (Solé \& Montoya, 2001), the field is suffering from a lack of comprehensive and manageable empirical systems. 
115 The representation of communities in networks constitutes a holistic approach, but the study

116 and interpretation of the drivers and consequences of the topology will largely depend on the

117 considered scale, both in terms of spatiotemporal and phylogenetic dimensions (Delmas et

118 al., 2019). While network studies at local scales will be informative on the local community

119 assembly processes, those reconstructed at regional or global scales will allow inference of

120 macro-ecological and evolutionary processes by making abstraction of the formerly

121 described local drivers (Trøjelsgaard \& Olesen, 2013).

In contrast to trophic networks, bipartite host-symbiont networks contain different kinds of links, with interactions between hosts and their symbionts ranging from antagonistic to mutualistic (Ings et al., 2009). Examples of such networks are for instance plant-mycorrhiza and host-microbiome associations. The complexity of these networks is enormous, and their description is merely based on one interaction type, either antagonistic or mutualistic, although theory predicts that the diversity of interaction types may be essential for community stability (Fontaine et al., 2011;Mougi \& Kondoh, 2012). The topology of bipartite host-symbiont networks can be dissected by adopting two different perspectives, i.e. that of each of the individual sets of species (hosts and symbionts). Asking what factors cause a given topology is equivalent to asking, for each of the sets, what explains the number of links per species and the specificity of these links, i.e. how links are distributed among species

134 from the focal set. An example of this approach is found in studies on predator-prey 135 networks, where average web vulnerability (i.e., the average number of predators per prey) and generality (i.e., the average number of prey eaten per predator) link the specificity of the two interacting species sets (Schoener, 1989). 
139 A determining feature of the ecology of symbionts is host specificity which can be quantified

140 in host-symbiont networks by the number of links departing from a symbiont node. Yet, a

141 measure of host specificity should ideally consider the relatedness of the targeted host

142 species as well (Poulin \& Mouillot, 2003). Generalist symbionts target multiple, unrelated

143 host species and are thought to gain relatively low benefits in any host. Specialist symbionts,

144 in turn, engage with one or only a few related species, but achieve high benefits with their

145 hosts relative to the generalists due to advanced morphological, physiological and

146 behavioural adaptations (Bronstein, Alarcón, \& Geber, 2006; Thrall et al., 2007). Their strong

147 specialization, however, is offset by lower population densities and higher extinction risks

148 due to the lower availability of hosts. Several studies in host-symbiont systems clearly found

149 that host specificity is tightly linked with fundamental ecological processes and evolutionary

150 history. Typically, host specificity is different among groups of the symbiont community as for

151 example demonstrated in parasites of primates (Pedersen et al., 2005) and in parasitic mites

152 on mussels (Edwards \& Malcolm, 2016). A study on moths and plants indicated that host

153 specificity can be dependent on the type of symbiotic interaction with pollinating moths being

154 more specific than the parasitic leaf-feeding relatives (Kawakita et al., 2010).

156 From the perspective of the host, it is fundamental to understand the ecological, evolutionary

157 and environmental drivers that promote the number of associated symbionts, i.e. the number

158 of links departing from a host node to symbiont nodes. Studies on other host-symbiont

159 systems reported multiple host variables which correlate with parasite species richness

160 (PSR). Generally, the makeup of symbiont communities is orchestrated by both ecological

161 and evolutionary host factors. The driving ecological factors are analogous to the ones that

162 favour species richness on islands (cf. theory of island biogeography, MacArthur \& Wilson, 163 1967) as host species can be regarded as biological islands (Kuris, Blaustein, \& Alio, 1980).

164 Symbiont richness is therefore expected to increase with the number and variety of 165 microhabitats offered by the host, host longevity, host range, and the interaction probability 
166 with other hosts (Kamiya et al., 2014; Stephens et al., 2016). Evolutionary processes may 167 affect symbiont species richness in different ways. Related hosts often show traits that are 168 correlated throughout evolution (phylogenetic correlation) which lead to similar values in species richness. However, related host species may have diverged with time, whether or 170 not in a common spatial evolutionary ancestry (biogeography), but may still attract a similar 171 fauna of symbionts as unrelated host species with a similar ecology (Poulin, 1995).

172 Another pattern that emerges in host-symbiont networks is the sharing/transmission of 173 symbiont species across host species. The degree of symbiont sharing is vital as symbiont 174 transmissions can connect eco-evolutionary dynamics across hosts as a result from rapid symbiont spread in host populations (e.g. Jaenike et al., 2010; Himler et al., 2011 in endosymbionts). While little is known about the proximate mechanisms by which single 177 symbionts switch between hosts, we can anticipate that host species with similar ecological 178 niches and/or a shared evolutionary history tend to have similar symbiont communities. The pervasive effect of phylogenetic relatedness on symbiont sharing has for example been demonstrated in bat parasites (Luis et al., 2015) and in plant-mycorrhiza (Veresoglou \& Rillig, 2014).

Ant-symbiont networks are ideally suited to study which factors drive bipartite network topology (Ivens et al., 2016). The diversity of symbiotic associations found in ants (Kistner,

184 1982; Hölldobler \& Wilson, 1990; Rettenmeyer et al., 2010; Parmentier, in press) is thought to be promoted by their omnipresence in terrestrial ecosystems, their stable and climatecontrolled nest fortresses and the high number of available resources in the nest (Kronauer \& Pierce, 2011). Ants interact with different types of symbionts spanning the entire parasitismmutualism gradient. They include parasitic ants, different groups of arthropods living in the nests, mutualistic aphids, nematodes, plants, bacteria and fungi. Therefore, they are ideal systems to study different interaction types in a single framework (Fontaine et al., 2011).

191 Ant-symbiont networks that have been recently studied, deal with local interaction networks and mostly focus on one kind of symbiotic interaction in isolation, such as mutualistic plant- 
193 ant networks (Guimaraes et al., 2006; Blüthgen et al., 2007; Dáttilo, Guimarães, \& Izzo, 194 2013; Cagnolo \& Tavella, 2015), mutualistic aphid-ant networks (Ivens et al., 2018) or 195 parasite-ant networks (Elizalde et al., 2018). A notable exception is the global meta-analysis 196 on different types of ant-symbiont interactions by Glasier, Poore, \& Eldridge (2018). 197 Unfortunately, this study only included a limited set of interaction types and pooled 198 interactions of well-studied bioregions with those of very poorly studied regions.

200 Here, we ask what factors explain the topology of ant-symbiont networks across Europe. We 201 firstly provide a quantitative and systematic meta-analysis on the diversity of European ant202 symbiont interactions. By adopting the symbiont perspective, we test the hypothesis that the 203 type of symbiosis explains the number and identity of their host species (host specificity). 204 More specifically, we expect that parasitic ants are more specific than the other types of 205 symbionts. In addition, we predict that different groups of symbiotic arthropods have highly 206 variable host specificity. Secondly, we follow a trait-based host perspective to identify the 207 major drivers that promote the diversity of ant-symbiont interactions and facilitate symbiont 208 sharing. We test the hypothesis that the number of symbionts with which an ant species 209 interacts and the number of symbionts it shares with other ant hosts depends on ecological 210 factors (6 factors, including colony size, nest type, distribution, habitat, degree of sympatry, 211 worker size) and evolutionary drivers (2 factors: phylogeny, biogeography) associated with 212 the host species. 


\section{II. MATERIAL AND METHODS}

\section{5 (1) Ant symbionts}

216 Symbionts are species that engage in a close association with a host species on which they

217 may have beneficial, neutral or adverse effects. We limited our analyses to Europe 218 (excluding the Canary Islands and Madeira), as ant-symbiont interactions in other continents 219 are extremely fragmentary studied and poorly understood. Moreover a myriad of unknown 220 symbionts are awaiting discovery and description in these continents (Parmentier, in press). 221 By contrast, a firm body of knowledge on the distribution and diversity of ant symbionts in 222 Europe has been recorded and has steadily grown from a long tradition of studying ant symbionts since the end of the 19th century (Wasmann, 1894; Janet, 1897). Depending on

224 the intimacy of the relationship between ants and symbionts, we can distinguish obligate and 225 facultative interactions. An obligate interaction occurs when a symbiont permanently lives inside or near an ant nest. Obligate symbionts completely depend on ants and cannot be found without them. Facultative myrmecophiles may associate with ants, but regularly (or mostly) occur without ants. In this study, we only focused on obligate symbionts.

We categorized five types of symbionts: (1) Trophobionts include aphids and scale insects that provide sugary honeydew in exchange of protection and hygienic services. These mutualistic arthropods are mostly found extranidally, except for aphids living on the roots of plants inside ant nests. (2) Myrmecophiles ss are a diverse group of arthropods that mostly live inside ant nests. Representatives of this group are distributed across many arthropod orders, but beetles and mites are the most diverse (Hölldobler \& Wilson, 1990; Kronauer \& Pierce, 2011). The life strategies of these organisms range from commensalism to specialized parasitism. (3) Social parasites encompass a group of ants that parasitize other ant species. There exist various types of social parasitism (see overview in Buschinger, 2009). In xenobiosis, cleptoparasitic ants construct a nest inside other ant nests, but raise 
240 the host work force to establish her own colony. Parasite workers will gradually substitute the

241 host worker force. In dulosis (permanent parasitism with slavery), a parasite colony is 242 established as in temporary parasitism. But here, the workers of the parasitic species will raid 243 pupae of other ant species. Workers which will emerge from these pupae will do most of the 244 tasks in the colony. In inquilinism (permanent parasitism without slavery), parasitic queens 245 permanently exploit a host colony and no worker force is produced. The parasitic queen 246 invests all her energy in producing sexuals. (4) ectoparasitic Fungi, (5) endoparasitic

247 Nematoda. Plants engaging in mutualistic relationships (e.g. myrmecochory) were not 248 included in our analyses. Contrary to the tropics, ant-plant relationships tend to be loose in 249 Europe and are at best facultative.

\section{1 (2) Ant-symbiont dataset compilation}

We compiled all documented ant-symbiont interactions in Europe. The database of antsymbiont interactions was assembled from 253 published references, including faunistic notes, research articles, reviews and books. In a first round of searches, we scanned reference works (e.g. Wasmann, 1894; Donisthorpe, 1927; Evans \& Till, 1966; Uppstrom, 2010; Tykarski, 2017; Molero-Baltanás et al. 2017) for associations between ant hosts and symbionts. Next we searched for ant-symbionts interactions via Google Scholar ${ }^{\mathrm{TM}}$ using the terms: "myrmecophile" or "ant associate" or "inquiline" or "ant guest" or "ant symbiont". We also found host-symbiont interactions within references that were cited in the retrieved publications. In a second phase, each symbiont occurring in Europe was then searched by its Latin binomial name and its common taxonomic synonyms combined with a search string with the names of all ant genera $(N=56$, AntWiki 2019) found in Europe (for example "Maculinea alcon" AND Acropyga OR Anochetus OR Aphaenogaster OR Bothriomyrmex OR

264 Camponotus OR ...) using Google Scholar. We chose Google Scholar over ISI Web of 265 Science, as the latter does not retrieve faunistic notes or other types of grey literature. We 266 omitted symbionts from our dataset when it was doubtful whether they are obligately 
267 associated with ants or not. Ultimately, we obtained a binary host-symbiont matrix filled with 268 interactions (1s) and non-interactions (0s) between ants (columns) and symbionts (rows). 269 Note that we included some references on ant-trophobiont interactions reported in the non270 European part of Russia (e.g. Novgorodova, 2005) to ramp up the relative modest number of 271 reported interactions in this type of association. The reported ants and trophobionts in these 272 references have a widespread Palearctic distribution and they are expected to interact in 273 Europe as well.

\section{5 (3) Host specificity in different symbiont types}

276 We compared the number of host species across different types of host symbionts. 277 Symbionts with only hosts identified at the genus level were not included in all following 278 analyses. Symbionts are unevenly studied, which may result in better studied symbionts 279 having a higher number of observed host species. To account for differences in sampling 280 effort, we therefore first regressed the total number of host species against the $(\ln +1)$ 281 transformed number of google scholar hits for the binomial species name (and commonly 282 used synonyms) of the symbionts. The residuals of this regression were then compared 283 across symbiont groups using a GLM, followed by Tukey post-hoc tests in R 3.5.2.

284 In a second analysis, we wanted to test whether the relatedness of targeted host species 285 varies among different symbiont groups. For each symbiont, we estimated the average taxonomic distance between the different hosts by using the specificity index, $S_{\text {TD }}$ proposed

287 by Poulin \& Mouillot (2003). Host ant species (all ants belong to the family Formicidae) were 288 classified following the Linnaean classification in subfamilies, tribes, genera and species 289 groups/subgenera. The taxonomic distance between two hosts is then defined as the number 290 of hierarchical steps that are needed to reach a common node in the taxonomic tree. The 291 taxonomic distance between two species of the same subgenus/species group equals to 1 , 292 the distance between two species of the same genus, but from a different subgenus/species 
293 group equals to 2. A maximum taxonomic distance of 5 is reached between two ant host 294 species from different subfamilies. $S_{\text {TD }}$ was estimated by averaging the taxonomic distance 295 across all pairs of host species. We modelled the specificity index against symbiont type with 296 a GLM followed by Tukey post-hoc tests. Symbiont species with a single reported host 297 species were omitted from this analysis, as no specificity index can be estimated for these 298 species (a total of 382 symbionts were retained in this analysis). In parallel, we reran this 299 analysis with a phylogenetic instead of a taxonomic distance matrix. The phylogenetic 300 distance matrix was based on the phylogenetic tree of European ants by Arnan et al. (2017).

301 Distances between species were estimated by node count (number of nodes along the 302 branches of the tree from one species to another) and were retrieved using Mesquite v.3.5. 303 Phylogenetic distances are more accurate than taxonomic distances to assess relatedness, 304 but unfortunately we do not possess phylogenetic information at the species level for all ants 305 in our dataset (phylogeny of 96 out of 177 ant species was known). We decided to drop the 30681 ant species without phylogenetic information and the corresponding interactions with their 307 symbionts for subsequent analyses. We believe that this is acceptable as these species only 308 cover $13.5 \%$ of the interactions in our host-symbiont dataset. We also omitted the exotic ant 309 species Linepithema humile, consequently we reduced our dataset to 95 ant species and 310602 symbionts. In addition, symbionts which interacted with only one ant species were 311 omitted, as no specificity index can be calculated for these species. Ultimately, we retained 312 349 symbiont species in this analysis.

\section{4 (4) Predictors of symbiont diversity in European ants}

315 A central question in this study is why some ant species host more symbionts than other ant 316 species. Therefore, we first compiled for the European ant species several predictors, based 317 on Arnan et al. (2017), Boulay et al. (2017), Seifert (2007) and AntWiki (2019) reflecting

318 differences in host functional niche. Predictors of symbiont diversity were extended traits of 319 the ant species and colony, including colony size (number of workers), average worker size 
320 (mm), nest type (levels: arboricolous, diverse, soil and organic mound) and phylogeny as a 321 proxy for trait similarity, and ecological factors of the ant species, including habitat (levels:

322

323

324

325

326

327

328

329

330

331

332

333

334 eurytope, introduced exote, open, open/sylvicolous and sylvicolous), distribution range, degree of sympatry and biogeographic region (levels: Atlantic, Boreomountain, Continental, Mediterranean, wide-ranging). Ants were assigned to the biogeographical region where they were found proportionally the most in sampled biogeographical regions based on the observations of Arnan et al. (2017). If the proportional occurrence in the most preferred region was less than double of the proportional occurrence in another region, the ant species was grouped under the "wide-ranging" category. We also estimated the distribution range (the number of countries where the host species has been reported, based on records on AntWiki, 2019), the degree of sympatry (number of ant species with symbionts which share at least one country in the distribution range, based on AntWiki, 2019) and the number of hits for their binomial name (and common synonyms) on google scholar as a proxy for sample effort for every ant species. Next we correlated total symbiont diversity with the host predictors described above, while correcting for the phylogenetic relatedness of the different ant species. The phylogenetic relatedness of host species should be accounted as closely related host species cannot be treated as independent observations. For that reason, we modelled a phylogenetic generalized least squares regression (PGLS) with total number of symbionts per ant species as dependent variable. A PGLS model incorporates a phylogenetic variance-covariance matrix in its error structure. We used the variancecovariance matrix based on the pairwise node counts retrieved from the phylogenetic tree of European ants by Arnan et al. (2017). The phylogenetic relatedness of 96 out of the 177 ant species found in our dataset was determined in this tree. We decided to drop the 81 ant species without phylogenetic information and the corresponding interactions with their symbionts for subsequent analyses. We believe that this is acceptable as these species only cover $13.5 \%$ of the interactions in our host-symbiont dataset. We also omitted the exotic ant species Linepithema humile, consequently we retained a dataset with 95 ant species and 602 symbionts. The phylogenetic covariance matrix was multiplied by Pagel's $\lambda$, a widely 
348 used parameter that scales and corrects for the expected degree of phylogenetic covariance 349 (Pagel, 1999). This multiplier spans from 0, which corresponds with the complete absence of 350 phylogenetic signal in the residuals of the model (the model is then similar to a regular GLM 351 with an ordinary least squares error structure) to 1, when the covariance of the model 352 residuals follows a Brownian motion model of evolution (Pagel, 1999; Freckleton, Harvey, \& 353 Pagel, 2002). The $\lambda$ parameter characterizing the phylogenetic signal was estimated through 354 maximum likelihood estimation within the PGLS model. We analysed this model using the 355 pgls function embedded in the R 3.5.1-package 'caper'. We transformed the variables to 356 meet the normality assumptions of the residuals. Number of symbionts was fourth root 357 transformed, the predictors colony size, degree of sympatry and google scholar hits In358 transformed, and the distribution range was square root transformed. Finally, all continuous 359 predictors were scaled to unit variance.

360 In addition to this analysis on the drivers of total symbiont diversity, we ran similar PGLS 361 models with subsets of symbiont species richness as dependent variables (overall number of 362 myrmecophiles, trophobionts, social parasites, and the diversity of the largest groups of 363 myrmecophiles, i.e. beetles and mites, separately) and predictors of the subset of ant

364 species that engage with these symbionts as predictors. Identical transformations of 365 predictors and subsets of symbiont richness were applied as in the analysis on total symbiont 366 richness described above. Diversity of social parasites and fungi were not regressed against 367 ant predictors in separate PGLS models as the number of host ants are relatively low in 368 these groups.

369 Models were ranked per analysis with the dredge function in 'MuMIn' R-package according to 370 their AICc-value (corrected Akaike Information Criterion). We retained the best models 371 identified with $\triangle \mathrm{AICC}<2$. Significance levels of the predictors of the retained models were 372 assessed using Likelihood ratio tests. 


\section{4 (5) Predictors of symbiont sharing in European ants}

375 Understanding the factors that facilitate or constrain the transmission of a symbiont from one 376 host to another, is pivotal in the study of host-symbiont networks. Here we assessed which 377 drivers promote the sharing of symbionts in ants. Predictors were similar to the previous 378 analysis and encompassed extended traits of the ant species and colony, including colony 379 size, worker size, nest type (levels: arboricolous, diverse, soil and organic mound) and phylogeny as a proxy for trait similarity; and ecological factors of the ant species, including

381 habitat (levels: eurytope, introduced exote, open, open/sylvicolous and sylvicolous), 382 distribution range, biogeographic region (levels: Atlantic, Boreomountain, Continental, 383 Mediterranean, wide-ranging) and degree of sympatry. We used multiple regression on 384 distance matrices (MRM), an extension of partial Mantel analysis, to test the association between different distance matrices (Lichstein, 2007). The dissimilarity symbiont matrix contained the pairwise Jaccard distances between each pair of host ants based on the presence-absence data of the symbionts they supported. This matrix was regressed against multiple distance matrices giving dissimilarities in the aforementioned predictors. Worker size distance was the absolute difference for this trait between every pair of ant species. The pairwise differences in colony size were In-transformed. The sympatry matrix listed the Intransformed number of countries in the distribution range that are shared between each pair of ant species. Entries in the distance matrices of habitat, nest type and biogeographic region were coded 0 when the pair of ants occupy the same habitat, nest type or biogeographic region, respectively, and 1 when the pair of ants show differences in these variables. The phylogenetic distances were the pairwise node counts. Again, we focused our analysis on the subset of 96 ants for which the phylogenetic relationship was resolved by Arnan et al. (2017). We also included a matrix of sampling effort in which we pairwise multiplied the $(\ln +1)$-transformed hits on google scholar of one ant species with the $(\ln +1)$-transformed hits on google scholar of another ant species. All matrices were standardized between 0 and 1 
401 package 'ecodist' using the MRM function. Significance of the predictor matrices was tested 402 using 9999 permutations. We removed non-significant predictors, and reran the MRM 403 analysis until all predictors were significant (Martiny et al., 2011). The relative importance of 404 the significant predictor matrices was calculated with the Img-metric, which uses unweighted 405 averages of sequential $\mathrm{R}^{2}$ of different orderings of the model predictors. The calculation and 406 visualization of the Img-metrics was conducted with the R-package 'relaimpo'.

407 We conducted similar MRM-analyses on subsets of the symbiont community, where the 408 response variable was the dissimilarity (pairwise Jaccard indices) in the set of 409 myrmecophiles, trophobionts, social parasites, myrmecophilous beetles and myrmecophilous 410 mites of the host ants, respectively. 


\section{III. RESULTS}

\section{2 (1) Ant-symbiont networks display a diversity of species interactions}

413 We identified 701 obligate ant symbionts interacting with 177 ant species in Europe 414 (Appendix S1). The references we used to compile the host-symbiont interaction matrix are 415 listed per symbiont species in Appendix S2. Myrmecophiles $(N=537)$ outnumbered the four 416 other groups of ant symbionts $(N=71, N=69, N=13$ and $N=11$ for respectively social 417 parasites, trophobionts, ectoparasites (all fungi) and endoparasites (all nematodes in our 418 analysis). Within the group of myrmecophiles, beetles and mites were the most species-rich 419 groups (Fig. 1). The hosts of 73 symbionts were not identified at the species level in the 420 literature record. The distribution of the number of host species per symbiont was right421 skewed $($ mean $=3.58$, median $=2)$. The highest frequency $(39 \%)$ of symbionts interacted 422 with 1 host species and a maximum number of 34 host species was documented in the 423 myrmecophilous silverfish Proatelurina pseudolepisma.

424 European ant genera contained a highly variable number of species (proportional to the 425 genus font size in Fig. 2, Fig. S1), ranging from 1 to 82 species, in the genera that interact 426 with symbionts. Generally, the species-rich ant genera, such as the Formicinae genera 427 Lasius, Formica and Camponotus and the Myrmicinae genera Messor and Myrmica attracted 428 a higher diversity of all five types of symbionts (Pearson's product-moment correlation: $r=$ $4290.60, P<0.001, d f=28$, Fig. S1). A notable exception was the species-richest European ant 430 genus Temnothorax, which supported a relatively moderate number of symbionts. 431 Myrmecophiles were the dominant group in most ant genera (mean $63.7 \%$ of the total 432 symbiont diversity). Trophobionts were generally the second most diverse group (mean $43314.9 \%$ ), but were absent or nearly absent in some genera such as Monomorium, 434 Aphaenogaster, Leptothorax, Messor and Cataglyphis. Social parasites slightly contributed to 435 total symbiont diversity in most ant genera (mean $8.9 \%$ ), but were very diverse in the ant 436 genera Temnothorax, Tertramorium and Leptothorax. Fungi (mean: 11.7\%) and nematodes 
437 (mean: $0.9 \%$ ) are also small symbiont groups. Interestingly, Myrmica is targeted by a 438 relatively high number of ectoparasitic fungi. Ant genera shared many symbionts (74.2\% on 439 average) with other genera, belonging to the same or different ant subfamilies (connecting 440 lines in Fig. 2). Temnothorax, Leptothorax and Messor are characterized by a relatively high 441 number of unique symbionts (cf. relative large inner circles in Fig. 2).

\section{3 (2) Host specificity in different symbiont types}

444 After controlling for sampling effort, host range of the symbiont groups was significantly 445 different (GLM, df $=25, P<0.001$, Fig. 3). Social parasites targeted the lowest number of 446 host species, whereas myrmecophilous Thysanura, Collembola and Isopoda are associated 447 with the highest number of ant hosts. Trophobionts also interacted with a relatively high 448 number of ant hosts (Fig. 3). Host range of symbiont groups without controlling for sampling 449 effort can be found in Fig. S2.

The average taxonomic distance between host species targeted by a symbiont was significantly different among the symbiont groups (GLM, $F=9.4$, df $=14, P<0.001$, Fig. 4).

452 Likewise, we found significant differences in average phylogenetic distance between host 453 species across the symbiont groups (GLM, $F=9.4$, df $=14, P<0.001$, Fig. S3). Patterns in 454 the average host phylogenetic distance of the different symbiont groups were closely 455 matching those of the average host taxonomic distance. The host species of social parasites 456 were very closely related to each other (Fig. 4 and S3). Fungi also exploited related host 457 species. Trophobionts, ectoparasitic nematodes and myrmecophiles interacted with hosts 458 that are much more unrelated. The group of myrmecophiles was heterogeneous and when 459 we subdivided it into different subgroups, we obtained an entire gradient in average host 460 taxonomic/phylogenetic distance (Fig. 4 and S3). 
463 The number of symbionts is highly variable in ant species. Here we report the host drivers 464 that affect total symbiont richness and diversity of subsets of ant symbionts (myrmecophiles, 465 trophobionts, social parasites, myrmecophilous mites and myrmecophilous beetles). Total 466 symbiont diversity was clearly positively correlated with colony size. This factor was highly 467 significant (PGLS, $P<0.001$ ) in the 4 top-ranking models (Table 1, Fig. 5). Habitat and 468 distribution range of the host were also incorporated in most of the top-ranking models. In 469 these models, symbiont richness increased with the host distribution range and was highest 470 in eurytopic habitats (PGLS, $\mathrm{P}<0.001$ ). As expected, sample effort has a major effect on the 471 reported total symbiont diversity and the five subsets of symbiont diversity. Symbiont 472 interactions were the highest in ants that are intensively studied. We controlled for sample 473 effort by including the proxy $(\operatorname{In}+1)$-transformed google scholar hits in our models. 474 Myrmecophile richness was also positively affected by colony size (PGLS, $P<0.001$ in the 5 475 top-ranking models, Table 1, Fig. 5), distribution and eurytopic habitat. The diversity of 476 myrmecophilous beetles was positively correlated with colony size and distribution range of 477 the host (PGLS, P-values < 0.001). Myrmecophilous mite diversity was also positively 478 correlated with colony size and distribution range (PGLS, P-values $<0.001$, Table 1 ) in all 479 retained models. Trophobiont diversity was mainly driven by sampling effort (PGLS, $\mathrm{P}<$ $480 \quad 0.001$, Fig. 5, Table 1). Trophobiont diversity was consistently highest in the Atlantic region 481 and in ant species with small workers. There were no predictors consistently present in the 482 top-ranking models explaining social parasite species richness (Table 1).

483 We did not find a phylogenetic signal in the predictors of the PGLS models $(\triangle \mathrm{AICc}<2)$ with 484 total symbiont, total myrmecophile, myrmecophilous beetle and myrmecophilous mite 485 diversity as dependent variables. The residuals of these models showed no phylogenetic 486 covariance (Pagel's $\lambda$ lambda was 0 , Table 1). In contrast, phylogenetic relatedness of the 487 hosts explained additional variation in the social parasite models (Pagel's $\lambda$ ranged between 4880.74 and 0.96 ) and to a lesser degree in the trophobiont models (Pagel $\lambda=0.30-0.42)$ (Table $4891)$. 


\section{(4) Predictors of symbiont sharing in European ants}

492 Here we examined whether the sharing of symbionts is affected by the similarity in particular

493 traits and ecological drivers of the host species. The maximum amount of variation explained

494 by our predictor matrices was in the subset of trophobionts $\left(R^{2}=37.1 \%\right.$, Fig. 6$)$. MRM

495 analyses aiming to explain similarities in particular groups of symbionts explained more 496 variation ( $\mathrm{R}^{2}$ ranging from $14.7 \%$ to $37.1 \%$ ) than those focusing on similarities in the total 497 symbiont community $\left(R^{2}=9.8 \%\right)$. Sample effort positively affected similarities in symbiont 498 communities including all symbionts (MRM, proportional contribution to the total $\mathrm{R}^{2}$ : Img = $4990.11, \mathrm{P}<0.001)$. Well-studied ant pairs also shared more trophobionts, social parasites, 500 myrmecophiles, myrmecophilous beetles and mites (MRM-analyses, Img ranging from 0.18 $501 \quad 0.58$, all P-values < 0.01, Fig. 6). The most important predictors of similarity (dissimilarity) in 502 ant symbiont communities in the European ant dataset were phylogenetic relatedness of the 503 ant hosts (1-distance) (MRM, Img $=0.40, P=0.001)$ and similarity (1-dissimilarity) in 504 biogeographic region $(\mathrm{MRM}, \mathrm{Img}=0.35, \mathrm{P}=0.001)$ (Fig. 6). Similarities in worker size and 505 colony size also facilitated the sharing of symbionts $(\mathrm{MRM}, \mathrm{Img}=0.08, \mathrm{P}=0.01$ and $\mathrm{Img}=$ $5060.05, P=0.02$, respectively, Fig. 6). Trophobiont sharing was also positively correlated with 507 phylogenetic relatedness and similarity in biogeographic regions of the ant hosts (MRM, Img $508=0.26, \mathrm{P}<0.001$ and $\mathrm{Img}=0.16, \mathrm{P}<0.001$, resp.). The similarities in social parasite 509 communities was largely explained by phylogenetic relatedness (MRM, Img $=0.53, \mathrm{P}<$ 510 0.001). Similarities in biogeography and colony size explained additional variation in the 511 sharing of social parasites (MRM, Img $=0.20, P<0.001$ and $\operatorname{Img}=0.05, P<0.05$ ). 512 Interestingly, phylogenetic relatedness of the hosts did not promote the sharing of 513 myrmecophiles and myrmecophilous mites. Host relatedness had only a minor effect on 514 myrmecophilous beetle sharing ( $\mathrm{MRM}, \mathrm{Img}=0.02, \mathrm{P}=0.03)$. The assemblage of 515 myrmecophiles, myrmecophilous beetles and mites was similar in pairs of ants occupying 516 identical biogeographic regions $(\mathrm{MRM}, \mathrm{Img}=0.57, \mathrm{P}<0.001$ and $\operatorname{Img}=0.38, \mathrm{P}<0.001$ and 
bioRxiv preprint doi: https://doi.org/10.1101/859058; this version posted November 29, 2019. The copyright holder for this preprint (which was not certified by peer review) is the author/funder. All rights reserved. No reuse allowed without permission.

$517 \mathrm{Img}=0.16, \mathrm{P}=0.02$, resp.) and having a large overlap in distribution (degree of sympatry)

518 (MRM, Img $=0.13, P=0.04$ and $\mathrm{Img}=0.24, \mathrm{P}=0.005$ and $\mathrm{Img}=0.28, \mathrm{P}=0.002$, resp.)

519 (Fig. 6). 


\section{$520 \quad$ IV. DISCUSSION}

521 Understanding the patterns of community assembly has been a central topic in ecology.

522 Community structuring and the underlying species interactions have been increasingly been 523 approached using network analysis. Yet, studies that describe and aim to understand the 524 topology of large-scale ecological networks consisting of different interaction types are 525 limited. We here provide a complete tally of the distribution of ant symbiont groups over 526 European ants and compare host specificity, symbiont richness, host switching and its 527 drivers for five different ant symbiont groups.

528

\section{9 (1) Characterization of the European ant-symbiont network}

It is widely acknowledged that the group of obligate ant symbionts is hyperdiverse 531 (Wasmann, 1894; Kistner, 1979, 1982; Hölldobler \& Wilson, 1990; Rettenmeyer et al., 2010), although exact species numbers at a regional scale are lacking. Rough estimates of the

533 global diversity of parasites living in ant nests reach 10.000 to 20.000 species (Thomas, 534 Schönrogge, \& Elmes, 2005), which is higher than mammal and bird diversity. We here 535 identified 701 obligate symbionts distributed over 177 ant species in Europe. The majority of the symbionts were classified as myrmecophiles, which are commensalistic to parasitic arthropods mostly living inside the nest of ants (Kronauer \& Pierce, 2011; Parmentier et al.,

538 2016; Parmentier, in press). The large diversity of this group is fuelled by the species-rich 539 myrmecophilous beetle and mite communities. In other regions, beetles and mites 540 outnumber other arthropod groups as well (Kistner, 1982; Hölldobler \& Wilson, 1990). Social 541 parasites and mutualistic trophobionts are medium-sized groups; parasitic nematodes and

542 fungi are relatively species-poor, but definitely understudied. Mutualistic ant symbionts are

543 thus clearly overshadowed by the diversity of commensalistic and parasitic ant symbionts in

544 Europe. Speciose ant genera and subfamilies generally supported higher numbers of ant 545 symbionts. Host-symbiont networks are characterized by an asymmetrical organization of 
546 interactions with host-specific symbionts and symbionts that interact with multiple host taxa

547 (Guimaraes et al., 2006). Overall, a large proportion of the symbionts were shared among

548 heterogeneric ant species (Fig. 2). Some ant genera interacted with a relatively low number

549 of symbionts, but most of their symbionts were not found in association with other ant

550 genera. The highly specific group of social parasites was much more represented in the

551 symbiont community of these hosts. In addition, the group of trophobionts is diverse in some

552 ant genera, but it is marginal or even absent in others (Fig. 2). The uneven distribution of the

553 five types of symbionts among the ant genera suggest that some ant lineages are more

554 predisposed to associate with particular types of symbionts. Ant-host associations are thus

555 shaped by deep evolutionary processes as determined by biotic and environmental drivers of

556 speciation and extinction (Aguilée et al., 2018).

557

558 (2) Host specificity in different symbiont types

559 Host specificity is a key feature of host-symbiont networks, and is moulded by the ecological

560 and evolutionary interactions between host and symbiont (Poulin \& Mouillot, 2003). Patterns

561 in host specificity have been studied in a wide range of host-symbiont systems. Generally,

562 parasites are thought to have a tendency to evolve to extreme host specialization as they

563 need complex adaptations to by-pass host defence (Kawakita et al., 2010). The drivers

564 favouring host specificity in mutualist partners are far less understood and both low and high

565 degrees of specificity are widespread (e.g. plant-seed dispersers and fig-fig wasps,

566 respectively). Ant symbioses are ideal to unravel patterns in host specificity. They occupy the

567 complete mutualism-parasitism continuum and allow comparison of host specificity in

568 different types of symbionts. We here demonstrate that average host range in European ant

569 symbionts was much broader than previously assessed in a study on host specificity of

570 myrmecophiles at a global scale (Glasier et al., 2018). The authors of this study state that

571 obligate ant symbionts occurred on average with ca. 1.20 host species. We, however, found

572 that European symbionts were reported with three times this number of host species (3.57) 
573 on average. The extreme low number of the detected hosts in the study of Glasier et al.

574 (2018) is the result of their searching method. They overlooked data hidden in faunistic 575 notes, grey literature and books, which report the majority of the interactions between ants 576 and their symbionts. Moreover, the symbiont fauna, let alone the range of their interactions, 577 is poorly documented outside Europe, which makes hard predictions unreliable (Parmentier, 578 in press). Ant symbionts were extremely variable in ant host range. After controlling for 579 sample effort, social parasites clearly targeted the lowest number of host species, which is in 580 line with the expectations as they are the most specialized group of parasites (Buschinger, 581 2009). The commensalistic myrmecophilous group of silverfish and the mutualistic

582 trophobionts engaged symbioses with the highest number of ant species. Apart from the 583 quantity of the hosts, the relatedness of the host species is a vital aspect of host specificity. It 584 is well described that social parasites colonize nests of related hosts (Buschinger, 2009). 585 However, this has never been compared with other type of symbiont groups. We showed that the hosts of social parasites were clearly the most related of all symbiont types. The hosts of myrmecophiles groups showed moderate to poor relatedness on average. Trophobionts and nematodes associated with distantly related ant species.

589 There is a large body of literature that explains the constraints of host switching in social 590 insect symbionts. Generally, it is thought that host-specific myrmecophiles and social parasites rely on chemical deception, by mimicking the colony recognition cues or some key pheromones (overview in Parmentier, Dekoninck, \& Wenseleers, 2017). They are completely

593 integrated in the host colony and are treated as a true colony member. Because of the strict 594 mimicking of the host's unique chemical profile, they are not able to colonize unrelated host 595 species. Generalist myrmecophiles are typically poorly integrated in the colony, but host 596 switching is more common in this group. It is facilitated by the use of general defensive 597 chemicals, chemical insignificance or behavioural strategies (Stoeffler, Tolasch, \& Steidle, 598 2011; Parmentier et al. 2017, 2018). The processes which make aphids attractive for one 599 host, but not for another are hitherto unexplored. Likewise, the factors that facilitate or 600 constrain host switching in parasitic nematodes and fungi are unknown. 


\section{2 (3) Predictors of symbiont diversity in European ants}

603 Associations between ant hosts and their symbionts are not random and structured

604 according to both ecological and evolutionary factors that act at different spatiotemporal 605 scales. From the perspective of ant symbionts, ant nests can be conceptualized as islands or 606 local patches connected through dispersal. In analogy with McArthur \& Wilson's island theory 607 and Leibold's metacommunity framework, larger ant nests interact with more symbiont 608 species. Ant nest size was repeatedly hypothesized as an important driver of ant symbiont 609 diversity (Hughes, Pierce, \& Boomsma, 2008; Kronauer \& Pierce, 2011), but here formally

610 tested for the first time. Previous studies across very different host-symbiont systems (e.g. 611 ectoparasites of fishes in Guégan et al., 1992, parasites of hoofed mammals in Ezenwa et 612 al., 2006, parasites of carnivores Lindenfors et al., 2007, feather mites of finches Villa et al., 613 2013) identified host body size as one of the key factors in determining symbiont species 614 richness (Kamiya et al., 2014). This positive association results from the fact that larger hosts 615 provide more niches and are less ephemeral (Lindenfors et al., 2007). Analogously, larger 616 ant nests provide more space to allow larger population sizes and thereby reducing the 617 extinction risk of symbionts. In addition, larger nests contain a higher diversity of 618 microhabitats, including refuge areas that eventually facilitate species coexistence (Barabás, 619 D'Andrea, \& Stump, 2018). Larger ant nests are also expected to be more persistent 620 (Kaspari \& Vargo, 1995). Colony size is thus a strong local driver of symbiont richness and 621 holding for myrmecophiles in particular. Myrmecophile diversity is additionally strongly 622 determined by more regional ecological factors like range size and niche width of the host 623 ants, so factors related to their general abundance and distribution. In that respect, eurytopic 624 ants, such as Lasius niger and Myrmica rubra that can live in a wide variety of habitats 625 including urban regions, hosted more symbionts. Both the effect of distribution and habitat 626 reflect that more symbionts occur in widely distributed ant species with high densities. 627 Symbionts associated with widely distributed ants are less prone to extinction as predicted by 
628 life history theory and metacommunity ecology (Nosil, 2002; Leibold et al., 2004). Host 629 density has widely been demonstrated as another key factor for explaining parasite species 630 richness (Lindenfors et al., 2007). Together with local colony sizes, sampling effects appear 631 highly relevant, hence more neutral drivers, of their diversity among different hosts. 632 Interestingly, trophobiotic and more specialised parasitic interactions as seen in the group of 633 social parasites are more determined by evolutionary drivers. Indeed, affinity with their hosts 634 is not only shaped by biogeography, hence a common spatial evolutionary ancestry but also 635 by phylogeny. The effect of phylogeny is echoed in the high Pagel's lambda values of the corresponding PGLS models, implying that much of the residual variation in trophobiont and 637 especially social parasite richness could be explained by the phylogeny of the hosts. The 638 strong phylogenetic driver for social parasite richness is in line with our previous results that 639 social parasites mainly target closely related ant species (referred to as Emery's rule, 640 Buschinger, 2009) belonging to a small number of ant genera. Symbiont network structure 641 thus shifts from more neutral ecological drivers related to regional species abundance to co642 evolutionary drivers related to ancestry. The uniqueness and tightness of species interaction 643 are known to be both a driver and consequence of co-evolutionary dynamics. Interestingly, 644 we here show these evolutionary drivers to overrule any ecological one in the most 645 antagonistic interactions, hence demonstrating the integrated nature of symbiont network 646 formation according to the prevailing interaction strengths. Ant-symbiont networks are quite 647 unique in the sense that the host associated network that is studied is covering a wide array 648 of interactions, from putatively mutualists to strictly antagonistic. Studies on specialised host649 parasite networks equally point at the dominance of evolutionary drivers (phylogeny and 650 biogeography) of these associations (Feliu et al., 1997; Rosas-Valdez \& de León, 2011), 651 while less obligatory animal parasitic (Nunn et al., 2003; Ezenwa et al., 2006; Lindenfors et 652 al., 2007; Nava \& Guglielmone, 2013) or plant mutualistic interactions (Sanders, 2003; 653 Wagner, Mendieta-Leiva, \& Zotz, 2015) show more ecological factors related to distribution 654 and abundance patterns that enhance contact and hence transmission of their diversity and 655 host association patterns. 


\section{7 (4) Predictors of symbiont sharing in European ants}

658 We hypothesized that the shared evolutionary history of related ant species would promote

659 the sharing of similar symbiont communities. The positive correlation between phylogenetic

660 relatedness of the hosts and symbiont sharing was demonstrated in previous studies on

661 orchid mycorrhiza (Jacquemyn et al., 2011) and bat viruses (Luis et al., 2015), but no such

662 relationship was found in arbuscular mycorrhiza (Veresoglou \& Rillig, 2014) and primate

663 parasites (Cooper et al., 2012). Consistent with our prediction, we found that the main factor

664 that promoted symbiont sharing in European ants was the relatedness of the hosts. It

665 indicates that many symbionts pass more easily to related host species. As related ant

666 species employ nearly identical defence structures (nestmate recognition cues, physiological

667 and behavioural defence), it enables symbionts, especially specialized parasites, to by-pass

668 the host defence systems of related hosts. Another key factor that may facilitate the cross-

669 species transmission of symbionts is the overlap in geographical distribution of the hosts (cf.

670 bat viruses in Luis et al., 2015). We showed that ant species living in the same

671 biogeographical region possessed more similar symbiont communities. This suggest that

672 both the spatial overlap and similarity in climatic conditions facilitate the sharing of

673 symbionts. Sampling effort also considerably explained the sharing of symbionts. More

674 shared symbionts were reported in well-studied pairs of species. Focusing on the different

675 subsets of ant symbionts, we found that the sharing of both trophobionts and social parasites

676 between host ant species was mainly determined by the same factors, i.e. sample effort,

677 biogeography and phylogenetic relatedness, that drive the sharing of the symbiont

678 community as a whole. However, phylogenetic relatedness was much more important in

679 explaining the sharing of social parasites. This effect is directly linked to the very low

680 taxonomic/phylogenetic distance between their hosts. Myrmecophiles as a whole and the

681 myrmecophilous beetle and mite communities were more similar in sympatric ant species

682 and ant species residing in the same biogeographical region. Interestingly, similarity in these 
683 symbiont communities was not positively correlated with host relatedness (cf. Cooper et al.,

684 2012; Veresoglou \& Rillig, 2014). The host range of myrmecophilous mites is clearly 685 understudied, which is visible in the relative importance of sample effort in the degree of mite 686 sharing.

687 V. OUTSTANDING QUESTIONS

688 [? Merging different interaction types into one ecological network framework is a key 689 challenge in ecology (Fontaine et al., 2011). Diverse host-symbiont communities 690 provide an opportunity to test the relative contributions of ecology and evolution to 691 network assembly. For example, our study on ant-symbiont networks reveal the 692 different role of ecological and evolutionary processes depending on the type of 693 symbiosis. Our insights may provide a basis for theory development and across694 ecosystem comparisons (e.g., against plant and coral-based networks) and synthesis. 695 We lack theory on how the architecture and the interaction signs and sizes jointly 696 affect the stability and productivity of these diverse networks, much in contrast to 697 trophic or mutualistic networks. The relative ease with which one can manipulate antsymbiont communities makes them suited as empirical systems to test theory.

[. Host-symbiont networks offer an opportunity to understand both ecological and evolutionary processes behind community assembly, from meso- to macro-ecological scale (see Vellend, 2016). More specifically, as hosts occur spatially structured at these scales, it remains an open question how these assembly processes are determined by ecological and evolutionary dispersal limitation. One key-question here is whether and how symbionts are dispersing: to what degree is horizontal transfer and subsequent symbiont sharing across hosts a facilitator of symbiont community assembly, and to which degree is an obligatory co-dispersal established across the antagonism-mutualism gradient of host-symbiont networks. Mutualistic plant 708 mycorrhizal fungi and plant diaspores are for instance passively co-dispersed by birds 
(Correia et al., 2019). Are alike active processes equally prevalent in ant-symbiont interactions, for instance by symbionts transported by their host during colony relocation (Parmentier, 2019)?

[. Different host species can coexist locally. In addition to stabilizing and equalizing mechanisms such as competition and niche differentiation, symbiont interactions may directly mediate coexistence of host species.

[ Insights from this review are restricted and applicable to networks as characterised at the species-level, thereby neglecting any intraspecific variation. Following the relevance of ecological and evolutionary determinants, the question remains open to which degree co-evolutionary dynamics between hosts and their symbiont community occur. As strong selection may act on ant symbionts to bypass host colony defence, cryptic speciation in ant symbionts is expected to be high (Schonrogge et al., 2002; Zagaja \& Staniec, 2015; von Beeren, Maruyama, \& Kronauer, 2015). Symbiont populations may be adapted to an individual host population as was demonstrated in the ant-parasitic syrphid fly Microdon and the butterfly Maculinea (Elmes et al., 1999; Tartally et al., 2019). Ultimately, population divergence may result in cryptic symbiont species each targeting a different host species.

[2 At a higher phylogenetic level, other Hymenopteran and insect lineages (Isoptera) provide similar niches to nest symbionts. Our review learned that none of the listed ant symbionts are shared with wasps, solitary and eusocial bees and termites (note that the latter two groups are poorly represented in Europe). Apparently only facultative symbionts (e.g., Porcellio scaber in wasp and bee nests for instance) are shared, but more study is needed to understand the drivers of host-symbiont divergence at these deep phylogenetic levels. 


\section{VI. CONCLUSIONS}

736 (1) Ant-symbiont networks are particularly interesting to study large-scales patterns and

737

738

739

740

741

742

743

744

745

746

747

748

749

750

751

752

753

754

755

756

757

758

759

760

761 drivers in host-symbiont network topology and symbiont richness as they are extremely diverse and cover the entire mutualism-antagonism continuum. We assembled a complete network of ant-symbiont interactions in Europe and comparatively studied the drivers of host specificity, symbiont richness and symbiont sharing in the different interaction sub-networks.

(2) We identified 701 obligate ant macrosymbionts which we categorized in five types: (1) trophobionts: mutualistic aphids and scale insects $(N=69)(2)$ myrmecophiles: commensalistic and parasitic arthropods $(N=537)$, (3) social parasites: parasitic ant species $(N=71)$, (4) ectoparasitic fungi $(N=13)$, and (5) endoparasitic nematodes $(N=11)$.

(3) The different types of ant symbionts significantly varied in host specificity. Apart from quantitative differences in host range, we also found clear differences in the average taxonomic/phylogenetic relatedness of the targeted host species for the different types of ant symbionts. The species-richest and best studied ant genera generally supported the largest number of symbionts, but the different types of symbionts were unevenly distributed across the ant genera.

(4) We revealed that the ecological and evolutionary factors which drive symbiont species richness may shift depending on the type of symbiosis. Myrmecophile species richness is mainly determined by ecological drivers, such as colony size, host range and niche width of the host. In contrast, species richness of trophobionts and social parasites is driven by evolutionary factors, such as host phylogeny and host biogeography.

(5) Ants living in the same biogeographic region shared more symbionts. The sharing of trophobionts and social parasites, in particular, was also strongly facilitated in phylogenetic

related

hosts. 


\section{VII. SUPPORTING INFORMATION}

763 Appendix S1. Host-symbiont matrix listing the associations between ants and ant-symbionts 764 in Europe.

765 Appendix S2. List of literature used to reconstruct the host-symbiont matrix in Appendix S1.

766 Fig. S1. Correlation between the number of described European species in an ant genus and 767 the number of supported symbionts.

768 Fig. S2. Number of host species per symbiont type. Box plots displaying the variation in the number of targeted host species within and across different types of ant symbionts. The width of the boxes is proportional to the square root of reported species in each

771 symbiont group. The different myrmecophilous arthropod orders are displayed in grey.

772

Fig. S3. Phylogenetic distance \pm SE, based on the phylogenetic tree of Arnan et al. (2017),

773 of targeted host species for different types of ant symbionts. The different

774 myrmecophilous arthropod orders are displayed in grey. Letter codes refer to Tukey

775 post-hoc test. Species with no letters in common are significant different $P<0.05$.

776

777

778 


\section{VIII. ACKNOWLEDGEMENTS}

780 This work was supported by Bijzonder Onderzoekfonds Ugent (BOF17/PDO/084 to TP) and

781 FWO (grant nr. 1203020N to TP). DB \& FdL are supported by the FWO research network 782 EVENET (W0.003.16N). 


\section{IX. REFERENCES}

785 Aguilée, R., Gascuel, F., Lambert, A. \& Ferriere, R. (2018). Clade diversification 786 dynamics and the biotic and abiotic controls of speciation and extinction rates. Nature 787 Communications 9, 1-13.

788 ANTWIKI (2019). AntWiki. http://www.antwiki.org/wiki/ [accessed 20 July 2012].

789 Arnan, X., Cerdá, X. \& RetanA, J. (2017). Relationships among taxonomic, functional, and 790 phylogenetic ant diversity across the biogeographic regions of Europe. Ecography 40, $791 \quad 448-457$.

792

BARABÁS, G., D’ANDREA, R. \& StUMP, S.M. (2018). Chesson's coexistence theory. Ecological 793 Monographs 88, 277-303.

794

795

796

797

798

799

800

801

802

803

804

805

806

BASCOMPTE, J. \& JORDANO, P. (2007). Plant-animal mutualistic networks: The architecture of biodiversity. Annual Review of Ecology, Evolution, and Systematics 38, 567-593.

BASCOMPTE, J., JoRdANO, P. \& Olesen, J.M. (2006). Asymmetric coevolutionary networks facilitate biodiversity maintenance. Science $312,431-433$.

Bastolla, U., fortuna, M.A., Pascual-García, A., Ferrera, A., luque, B. \& Bascompte, J. (2009). The architecture of mutualistic networks minimizes competition and increases biodiversity. Nature 458, 1018-1020.

Blüthgen, N., Menzel, F., Hovestadt, T., FialA, B. \& Blüthgen, N. (2007) Specialization, constraints, and conflicting interests in mutualistic networks. Current Biology 17, 341346.

Boulay, R., Aron, S., Cerdá, X., Doums, C., Graham, P., Hefetz, A. \& Monnin, T. (2017). Social life in arid environments: The case study of Cataglyphis ants. Annual Review of Entomology 62, 305-321. 
807 Bronstein, J.L., Alarcón, R. \& Geber, M. (2006). The evolution of plant-insect mutualisms. $808 \quad$ New Phytologist 172, 412-428.

809

BUSCHINGER, A. (2009). Social parasitism among ants $\square$ : a review (Hymenoptera $\square$ : $810 \quad$ Formicidae). Myrmecological News 12, 219-235.

811 Cagnolo, L. \& TAVELLA, J. (2015). The network structure of myrmecophilic interactions. $812 \quad$ Ecological Entomology 40, 553-561.

813 Cooper, N., Griffin, R., Franz, M., Omotayo, M. \& NunN, C.L. (2012). Phylogenetic host 814 specificity and understanding parasite sharing in primates. Ecology Letters 15, 13708151377.

816 Correia, M. , Heleno, R. , da, Silva, L. P., Costa, J. M. \& Rodríguez-Echeverría, S. 817 (2019), First evidence for the joint dispersal of mycorrhizal fungi and plant diaspores by 818 birds. New Phytologist Trust 222: 1054-1060.

819

DARWIN, C. (1859). On the Origin of the Species, or the Preservation of Favoured Races in 820 the Struggle for Life. John Murray, London, UK.

821

DÁTTILO, W., GuIMARÃES, P.R. \& IZZO, T.J. (2013). Spatial structure of ant-plant mutualistic 822 networks. Oikos 122, 1643-1648.

823

Delmas, E., Besson, M., Brice, M.H., Burkle, L.A., Dalla Riva, G. V., Fortin, M.J., 824 Gravel, D., Guimarães, P.R., Hembry, D.H., Newman, E.A., Olesen, J.M., Pires, 825 M.M., YEAKEL, J.D. \& POISOT, T. (2019). Analysing ecological networks of species 826 interactions. Biological Reviews 94, 16-36.

DONISTHORPE, H.S.J.K. (1927). The guests of British ants, their habits and life-histories. George Routledge and Sons, London.

EdWARDS, D. \& MALCOLM, F. (2016). Host Specificity among Unionicola spp. (Acari $\square$ : $830 \quad$ Unionicolidae) parasitizing freshwater mussels. The Journal of Parasitology 92, 977983. 
832 Elizalde, L., Patrock, R.J.W., Disney, R.H.L. \& Folgarait, P.J. (2018). Spatial and 833 temporal variation in host-parasitoid interactions: leafcutter ant hosts and their phorid 834 parasitoids. Ecological Entomology 43, 114-125.

835 Elmes, G.W., BarR, B., Thomas, J.A. \& ClaRKe, R.T. (1999). Extreme host specifcity by 836 Microdon mutabilis (Diptera $\square$ : Syrphidae), a social parasite of ants. Proceedings of the 837 Royal Society London B 266, 447-453.

838 Evans, G.O. \& TILL, W.M. (1966). Studies on the British Dermanyssidae (Acari: 839 Mesostigmata) Part II. Classification. Bulletin of The British Museum (Natural History) $840 \quad$ Zoology 14, 107-370.

841 Ezenwa, V.O., Price, S.A., Altizer, S., Vitone, N.D. \& CoOK, K.C. (2006). Host traits and 842 parasite species richness in even and odd-toed hoofed mammals, Artiodactyla and 843 Perissodactyla. Oikos 115, 526-536.

844 Feliu, C., Renaud, F., Catzeflis, F., Hugot, J.P., Durand, P. \& Morand, S. (1997). A 845 comparative analysis of parasite species richness of Iberian rodents. Parasitology 115, $846 \quad 453-466$.

847 Fontaine, C., Guimarães, P.R., Kéfi, S., Loeullle, N., Memmott, J., van der Putten, W.H., 848 VAN VEen, F.J.F. \& THÉBAULT, E. (2011). The ecological and evolutionary implications of 849 merging different types of networks. Ecology Letters 14, 1170-1181.

850 Freckleton, R.P., Harvey, P.H. \& Pagel, M. (2002). Phylogenetic analysis and 851 comparative data: a test and review of evidence. The American Naturalist 160, 712-726.

852 GuÉgan, J., Lambert, A., LÉvÊQue, C., Combes, C. \& Euzet, L. (1992). Can host body size 853 explain the parasite species richness in tropical freshwater fishes? Oecologia 90, 197854204.

855 Glasier, J.R.N., PoORE, A.G.B. \& EldRIDGE, D.J. (2018). Do mutualistic associations have 856 broader host ranges than neutral or antagonistic associations? A test using 
myrmecophiles as model organisms. Insectes Sociaux 65, 639-648.

858 Guimarães, P.R., Rico-Gray, V., dos ReIS, S.F. \& ThOMPSON, J.N. (2006). Asymmetries in 859 specialization in ant-plant mutualistic networks. Proceedings of the Royal Society B: $860 \quad$ Biological Sciences 273, 2041-2047.

861 HaIRStON, N.G., SMith, F.E. \& SLOBOdKIN, L.B. (1960). Community structure, population 862 control, and competition. The American Society of Naturalists 94, 421-425.

863

864

865

866

867

868

869

870

871

872

873

874

875

876

877

878

879

880

Himler, A.G., Adachi-Hagimori, T., Bergen, J.E., Kozuch, A., Kelly, S.E., Tabashnik, B.E., Chiel, E., Duckworth, V.E., Dennehy, T.J., Zchori-Fein, E. \& Hunter, M.S. (2011). Rapid spread of a bacterial symbiont in an invasive whitefly is driven by fitness benefits and female bias. Science 332, 254-256.

Hölldobler, B. \& Wilson, E.O. (1990). The ants. Harvard University Press, Cambridge, Massachusetts.

Hughes, D.P., Pierce, N.E. \& BoOmsma, J.J. (2008). Social insect symbionts: evolution in homeostatic fortresses. Trends in Ecology and Evolution 23, 672-677.

Ings, T.C., Montoya, J.M., Bascompte, J., Blüthgen, N., Brown, L., Dormann, C.F., Edwards, F., FigueroA, D., Jacob, U., Jones, J.I., LAURIDSEN, R.B., LedGeR, M.E., LeWis, H.M., Olesen, J.M., Van Veen, F.J.F., WarRen, P.H. \& WoOdWard, G. (2009). Ecological networks - Beyond food webs. Journal of Animal Ecology 78, 253-269.

Ivens, A.B.F.,von Beeren, C., Blüthgen, N. \& Kronauer, D.J.C. (2016). Studying the complex communities of ants and their symbionts using ecological network analysis. Annual Review of Entomology 61, 353-371.

IVens, A.B.F., Gadau, A., Kiers, E.T. \& Kronauer, D.J.C. (2018). Can social partnerships influence the microbiome? Insights from ant farmers and their trophobiont mutualists. Molecular Ecology 27, 1898-1914. 
882 B. (2011). Analysis of network architecture reveals phylogenetic constraints on 883 mycorrhizal specificity in the genus Orchis (Orchidaceae). New Phytologist 192, 518884528.

885 Jaenike, J., Unckless, R., Cockburn, S.N., Boelio, L.M. \& Perlman, S.J. (2010). 886 Adaptation via symbiosis: Recent spread of a drosophila defensive symbiont. Science $887 \quad 329,212-215$.

888 JANET, C. (1897). Etudes sur les fourmis, les guêpes et les abeilles. Note 14: Rapports des 889 animaux myrmécophiles avec les fourmis. Ducourtieux, Limoges.

890 Kamiya, T., Dwyer, K.O., Nakagawa, S. \& Poulin, R. (2014). What determines species 891 richness of parasitic organisms $\square$ ? A meta-analysis across animal, plant and fungal 892 hosts. Biological reviews 89, 123-134.

KASPARI, M. \& VARGO, E.L. (1995). Colony size as a buffer against seasonality: Bergmann's 894 rule in social insects. The American Naturalist 145, 610-632.

895

KaWAKITA, A., Окамото, T., Goto, R. \& Kato, M. (2010). Mutualism favours higher host 896 specificity than does antagonism in plant-herbivore interaction. Proceedings of the Royal Society B: Biological Sciences 277, 2765-2774.

KISTNER, D.H. (1979). Social and evolutionary significance of social insect symbionts. In 899 Social Insects, Volume I (ed H.R. HERMAN), pp. 339-413. Academic Press.

900 KIStneR, D.H. (1982). The social insects' bestiary. In Social Insects, Vol III (ed H.R. 901 Herman), pp. 1-244. Academic Press.

902 Kronauer, D.J.C. \& Pierce, N.E. (2011). Myrmecophiles. Current biology 21, 208-209.

903 Kuris, A.M., Blaustein, A.R. \& AliO, J.J. (1980). Hosts as islands. The American naturalist $904 \quad 116,570-586$.

905 Leibold, M.A., Holyoak, M., Mouquet, N., Amarasekare, P., Chase, J.M., Hoopes, M.F., 906 Holt, R.D., Shurin, J.B., LaW, R., Tilman, D., Loreau, M. \& Gonzalez, A. (2004). The 
metacommunity concept: A framework for multi-scale community ecology. Ecology

908 Letters 7, 601-613.

909

LICHSTEIN, J.W. (2007). Multiple regression on distance matrices $\square$ : a multivariate spatial

910 analysis tool. Plant Ecology 188, 117-131.

911 Lindenfors, P., Nunn, C.L., Jones, K.E., Cunningham, A.A., Sechrest, W. \& Gittleman, 912 J.L. (2007). Parasite species richness in carnivores: Effects of host body mass, latitude, 913 geographical range and population density. Global Ecology and Biogeography 16, 496914509.

915 LUIS, A.D., O’SheA, T.J., Hayman, D.T.S., WoOd, J.L.N., Cunningham, A.A., Gilbert, A.T., 916 MiLlS, J.N. \& WEBB, C.T. (2015). Network analysis of host-virus communities in bats 917 and rodents reveals determinants of cross-species transmission. Ecology Letters 18, $918 \quad 1153-1162$

919 MacARthuR, R.H. \& Wilson, E.O. (1967). The theory of island biogeography. Princeton $920 \quad$ University Press.

921 Martiny, J.B.H., Eisen, J.A., Penn, K., Allison, S.D. \& Horner-Devine, M.C. (2011). 922 Drivers of bacterial $\beta$-diversity depend on spatial scale. PNAS 108, 7850-7854.

923 Molero-Baltanás, R., Bach De Roca, C., Tinaut, A., Pérez, J.D. \& Gaju-Ricart, M. 924 (2017). Symbiotic relationships between silverfish (Zygentoma: Lepismatidae, 925 Nicoletiidae) and ants (Hymenoptera: Formicidae) in the Western Palaearctic. A 926 quantitative analysis of data from Spain. Myrmecological News 24, 107-122.

927 Mougl, A. \& KONDOH, M. (2012). Diversity of interaction types and ecological community $928 \quad$ Stability. Science 337, 349-351.

929 NAva, S. \& Guglielmone, A.A. (2013). A meta-analysis of host specificity in Neotropical hard 930 ticks (Acari: Ixodidae). Bulletin of Entomological Research 103, 216-224.

931 NeWman, M.E.J. (2003). The structure and function of complex networks. SIAM Review 45, 
933 NosIL, P. (2002). Transition rates between specialization and generalization in phytophagous $934 \quad$ insects. Evolution 56, 1701-1706.

935

Novgorodova, T.A. (2005). Red wood ants (Formicidae) impact on multi-species complexes

936 of aphids (Aphididae) in the forest-park zone of Novosibirsk. Euroasian Entomological

937 Journal 4, 117-120.

938

Nunn, C.L., Altizer, S., Jones, K.E., Sechrest, W., Nunn, C.L., Altizer, S., Jones, K.E. \&

939 SECHREST, W. (2003). Comparative tests of parasite species richness in primates. The American naturalist 162, 597-614.

941

Olesen, J.M., BAscompte, J., Dupont, Y.L. \& JoRdAno, P. (2007). The modularity of 942 pollination networks. Proceedings of the National Academy of Sciences of the United $943 \quad$ States of America 104, 19891-19896.

944 PAGEL, M. (1999). Inferring the historical patterns of biological evolution. Nature 401, 877945884.

PARACER, S. \& AHMADJIAN, V. (2000). Symbiosis: an introduction to biological associations. 947 Oxford University Press, New York.

948 PARMEntieR, T. (2019). Host following of an ant associate during nest relocation. Insectes $949 \quad$ Sociaux 66, 329-333.

950 PARMEnTIER, T. (in press). Guests of social insects. In Encyclopedia of Social Insects (ed $951 \quad$ C.K. Starr). Springer.

Parmentier, T., Bouillon, S., Dekoninck, W. \& Wenseleers, T. (2016). Trophic 953 interactions in an ant nest microcosm: a combined experimental and stable isotope (ס13C/ठ15N) approach. Oikos 125, 1182-1192.

955 Parmentier, T., Dekoninck, W. \& Wenseleers, T. (2017). Arthropods associate with their 
956

957

958

959

960

961

962

963

964

965

966

967

968

969

970

971

972

973

974

975

976

977

978

979

980

red wood ant host without matching nestmate recognition cues. Journal of Chemical Ecology 43.

Parmentier, T., De Laender, F., Wenseleers, T. \& Bonte, D. (2018). Prudent behavior rather than chemical deception enables a parasite to exploit its ant host. Behavioral Ecology 29, 1225-1233.

Pedersen, A.B., Altizer, S., Poss, M., Cunningham, A.A. \& Nunn, C.L. (2005). Patterns of host specificity and transmission among parasites of wild primates. International Journal for Parasitology 35, 647-657.

PIMM, S.L. (1979). Complexity and stability $\square$ : another look at MacArthur's original hypothesis. Oikos 33, 351-357.

Poulin, R. (1995). Phylogeny, ecology, and the richness of parasite communities in vertebrates. Ecological Monographs 65, 283-302.

POULIN, R. \& MOUILLOT, D. (2003). Parasite specialization from a phylogenetic perspective: A new index of host specificity. Parasitology 126, 473-480.

Rettenmeyer, C.W., Rettenmeyer, M.E., Joseph, J. \& Berghoff, S.M. (2010). The largest animal association centered on one species: the army ant Eciton burchellii and its more than 300 associates. Insectes Sociaux 58, 281-292.

Rosas-Valdez, R. \& DE LeÓn, G.P.-P. (2011). Patterns of host specificity among the helminth parasite fauna of freshwater siluriforms: Testing the biogeographical core parasite fauna hypothesis. Journal of Parasitology 97, 361-363.

SANDERS, I.R. (2003). Preference, specificity and cheating in the arbuscular mycorrhizal symbiosis. Trends in Plant Science 8, 143-145.

SCHOENER, T.W. (1989). Food webs from the small to the large: the Robert H. MacArthur award lecture. Ecology 70, 1559-1589.

Schönrogge, K., Barr, B., Wardlaw, J., Napper, E., Gardner, M., Breen, J., Elmes, G. \& 
981

982

983

984

985

986

987

988

989

990

991

992

993

994

995

996

997

998

999

1000

1001

1002

1003

1004

1005

THOMAS, J.A. (2002). When rare species become endangered: Cryptic speciation in myrmecophilous hoverflies. Journal of the Linnean Society 75, 291-300.

SEIFERT, B. (2007). Die Ameisen Mittel- und Nordeuropas. lutra Verlags- und Vertriebsgesellschaft, Tauer.

SOlÉ, R. V. \& MONTOYA, J.M. (2001). Complexity and fragility in ecological networks. Proceedings of the Royal Society B: Biological Sciences 268, 2039-2045.

SOLÉ, R. V \& BASCOMPTE, J. (2006). Self-Organization of Complex Ecosystems (MPB-42). Princeton University Press.

Stephens, P.R., Altizer, S., Smith, K.F., Alonso Aguirre, A., Brown, J.H., Budischak, S.A., Byers, J.E., Dallas, T.A., Jonathan Davies, T., Drake, J.M., Ezenwa, V.O., Farrell, M.J., Gittleman, J.L., Han, B.A., Huang, S., et AL. (2016). The macroecology of infectious diseases: a new perspective on global-scale drivers of pathogen distributions and impacts. Ecology letters 19, 1159-1171.

Stoeffler, M., Tolasch, T. \& Steidle, J.L.M. (2011). Three beetles-three concepts. Different defensive strategies of congeneric myrmecophilous beetles. Behavioral Ecology and Sociobiology 65, 1605-1613.

Tartally, A., Thomas, J.A., Anton, C., Balletto, E., Barbero, F., Bonelli, S., BräU, M., Casacci, L. Pietro, Csósz, S., Czekes, Z., Dolek, M., Dziekanska, I., Elmes, G., FÜRST, M.A., GLINKA, U., ET AL. (2019). Patterns of host use by brood parasitic Maculinea butterflies across Europe. Proceedings of the Royal Society B $\mathbf{3 7 4}$, 20180202.

THOMAS, J.A., SCHÖNROGGE, K. \& ELMES, G.W. (2005). Specializations and host associations of social parasites of ants. In Insect Evolutionary Ecology (eds M.D.E. FELLOWES, G.J. HOLLO \& J. RoLFF), pp. 479-518. Royal Entomological Society, CABI Publishing, UK.

Thrall, P.H., Hochberg, M.E., BuRdon, J.J. \& BeVER, J.D. (2007). Coevolution of symbiotic 
mutualists and parasites in a community context. Trends in Ecology and Evolution 22,

1007 $120-126$.

TILMAN, D. (1982). Resource competition and community structure. Princeton University $1009 \quad$ Press.

TrøjelsgaARD, K. \& Olesen, J.M. (2013). Macroecology of pollination networks. Global Ecology and Biogeography 22, 149-162.

1012 TYKARSKI, P. (2017). Coleoptera Poloniae - Information System about Beetles of Poland. $1013 \quad$ http://coleoptera.ksib.pl/?l=en.

UPPSTROM, K.A. (2010). Mites (Acari) associated with the ants (Formicidae) of Ohio and the harvester Ant, Messor pergandei, of Arizona. Master thesis, Ohio State University.

VÁZQUEZ, D.P., ChacofF, N.P. \& CAGNOLO, L. (2009). Evaluating multiple determinants of 1017 the structure of plant-animal mutualistic networks. Ecology 90, 2039-2046.

1018 Vellend, M. (2016). The Theory of Ecological Communities (MPB-57), Vol. 75. Princeton $1019 \quad$ University Press.

1020

1021

VERESOGLOU, S.D. \& RILLIG, M.C. (2014). Do closely related plants host similar arbuscular mycorrhizal fungal communities $\square$ ? A meta-analysis. Plant and Soil 377, 395-406.

Villa, S.M., Le BOHEC, C., KoOP, J.A.H., Proctor, H.C. \& Clayton, D.H. (2013). Diversity of feather mites (Acari: Astigmata) on Darwin's finches. Journal of Parasitology 99, 756762.

von Beeren, C., Maruyama, M. \& Kronauer, D.J.C. (2015). Cryptic diversity, high host specificity and reproductive synchronization in army antassociated Vatesus beetles. Molecular Ecology 25, 990-1005.

WAGner, K., MendietA-Leiva, G. \& ZotZ, G. (2015). Host specificity in vascular epiphytes: A review of methodology, empirical evidence and potential mechanisms. AoB PLANTS 7, 
$1030 \quad 1-25$.

1031 WASMANN, E. (1894). Kritisches Verzeichniss der myrmekophilen und termitophilen 1032 Arthropoden. Berlin: F. L. Dames, xv.

1033 ZagajA, M. \& Staniec, B. (2015). Thiasophila szujeckii sp. n. (Coleoptera, Staphylinidae, 1034 Aleocharinae) - a cryptic species associated with Formica truncorum in Poland. Zootaxa $1035 \quad 3955,417-426$.

1036

1037 
1038

1039

1040

1041

1042

1043

1044

1045

1046

1047

1048

1049

1050

1051

1052

1053

1054

1055

1056

1057

1058

1059

1060

1061

1062

1063

\section{FIGURE LEGENDS}

FIGURE 1. Distribution of different types of ant symbionts. Total number of symbionts $N=$ 701 , number of symbionts per type given in brackets.

FIGURE 2. Ant symbiont network displaying the proportional distribution of symbionts across the European ant genera. A multilevel pie chart is given for each ant genus. The size of the outer pie chart corresponds to the total number of associated symbionts. The size of the inner pie chart is related to the number of symbionts that are not shared with other ant genera (unique symbionts). The proportional distribution of the five types of ant symbionts is given for all associated symbionts (colour segments in outer pie charts) and for the symbionts that are not shared with other genera (colour slices in inner pie charts). The relative proportion of unique symbionts can be deduced by the relative size of the inner circle to the outer circle. The genera are organized in four groups, corresponding to the ant subfamily to which they belong. The genera are connected with lines, of which the width is directly proportional to the number of shared symbionts. The font size of a genus is proportional to its number of described species in Europe.

FIGURE 3. Number of host species per symbiont type, controlled for sampling effort \pm SE. The different myrmecophilous arthropod orders are displayed in grey. Letter codes refer to Tukey post-hoc test. Species with no letters in common are significant different $\mathrm{P}<$ 0.05 .

FIGURE 4. Taxonomic distance \pm SE of targeted host species for different types of ant symbionts. The different myrmecophilous arthropod orders are displayed in grey. Letter codes refer to Tukey post-hoc test. Species with no letters in common are significant different $\mathrm{P}<0.05$. 
1065 FIGURE 5. Ranking of the predictors from the six PGLS models by the corrected Akaike 1066 information criterion $(\triangle \mathrm{AICC})$. The change in AICc when adding or removing a variable 1067 from the most optimal model is compared. Predictors included in the most optimal 1068 model are removed ( $\triangle \mathrm{AICc}$ positive), whereas those not included are added $(\triangle \mathrm{AICc}$ 1069 negative) to the best model (lowest AICc). The ranking is given for the six PGLS 1070 analyses, i.e. with dependent variable the number of symbionts (best model: sample 1071 effort + colony size + distribution + habitat), trophobionts (best model: $\sim$ sample effort + 1072 biogeographic region + worker size + sympatric ants), social parasites (best model: sympatric ants), myrmecophiles (best model: sample effort + colony size + distribution + habitat), myrmecophilous beetles (Coleoptera) (best model: colony size + sample effort + distribution range) and myrmecophilous mites (Acari) (best model: colony size + habitat + distribution range + sample effort), respectively. Note that mites and beetles are nested within the group of myrmecophiles and myrmecophiles, trophobionts and social parasites are three subsets of all ant-associated symbionts.

1079

FIGURE 6. Relative importance of the significant predictor matrices explaining the dissimilarity in symbiont communities across different ant species. Rankings are given for predictors explaining overall dissimilarity (1-similarity) in symbiont composition, and for dissimilarity in subsets of symbiont composition: trophobionts, social parasites, myrmecophiles, myrmecophilous beetles and mites, respectively. Note that beetles and mites are nested within the group of myrmecophiles, and myrmecophiles, trophobionts and social parasites are three subsets of all ant-associated symbionts. The allocated contribution (sequential $\mathrm{R}^{2}$ ) of the different distance matrices (indicated with $\Delta$ ) or other predictor matrices (sample effort and 1-sympatry) to the explained variation of the MRM models is estimated with the Img-metric. All predictor matrices are positively correlated with dissimilarity in symbiont composition. Significance levels of the predictors were tested with a permutation test $\left(\mathrm{n}=9999, \mathrm{P}<0.001\right.$ : ${ }^{* *}, \mathrm{P}<0.01$ : $^{* *}, \mathrm{P}<0.05$ : ${ }^{*}, \mathrm{P}<$ 0.10:"). 


\section{FIGURES}

1094

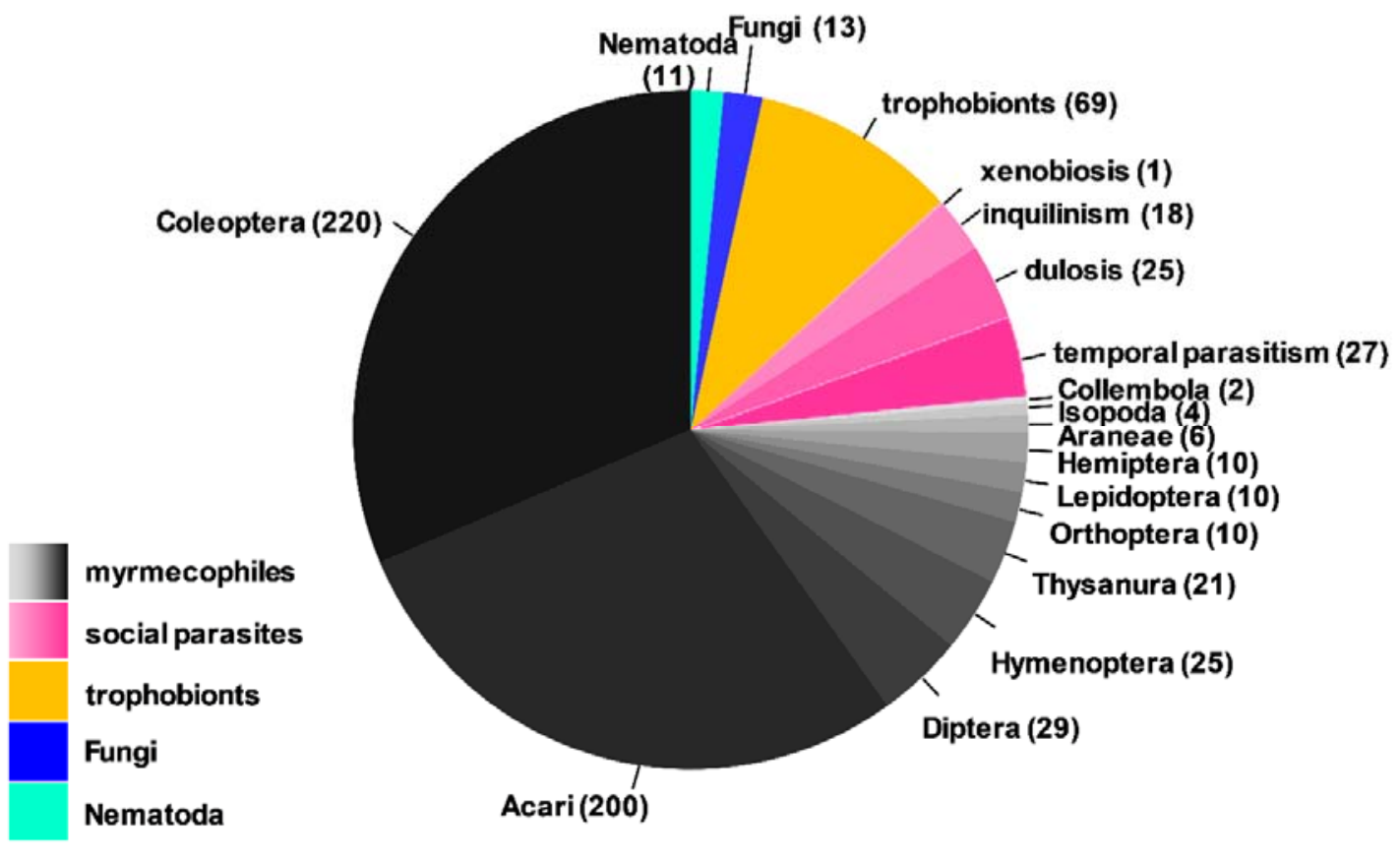

1095 Fig. 1 
bioRxiv preprint doi: https://doi.org/10.1101/859058; this version posted November 29, 2019. The copyright holder for this preprint (which was not certified by peer review) is the author/funder. All rights reserved. No reuse allowed without permission.

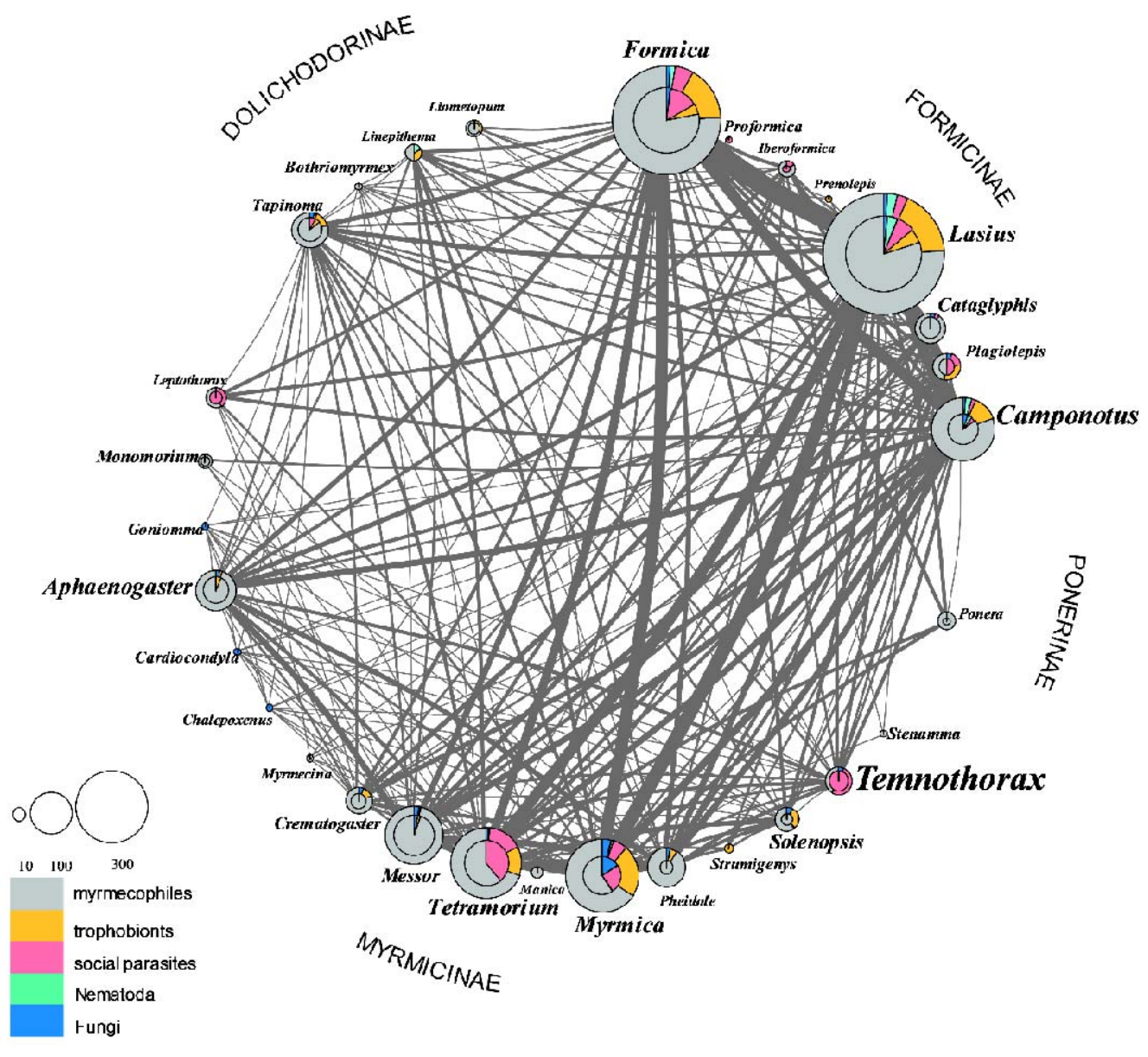

1097

Fig.2 


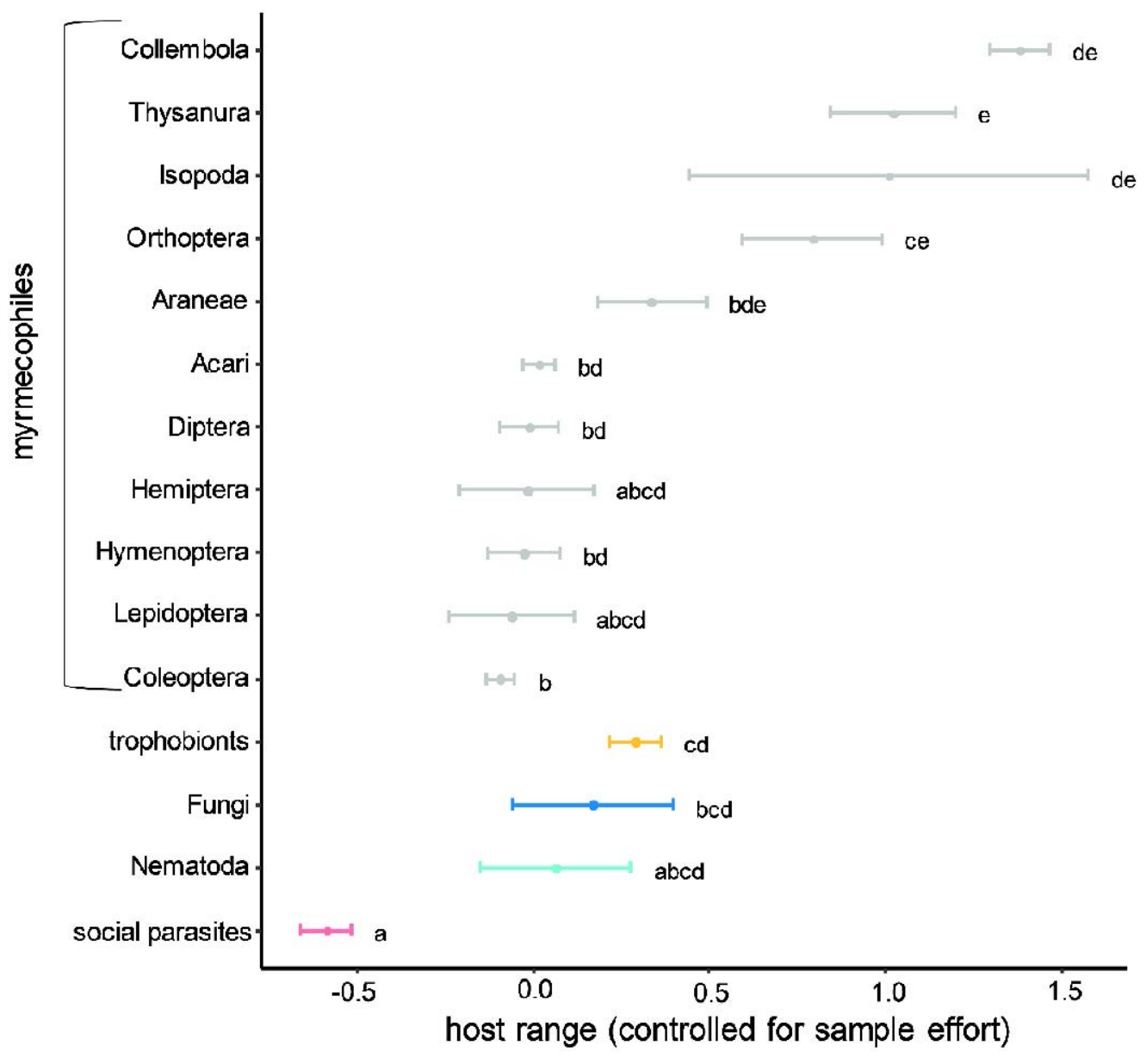

$1099 \quad$ Fig. 3

1100

1101

1102 


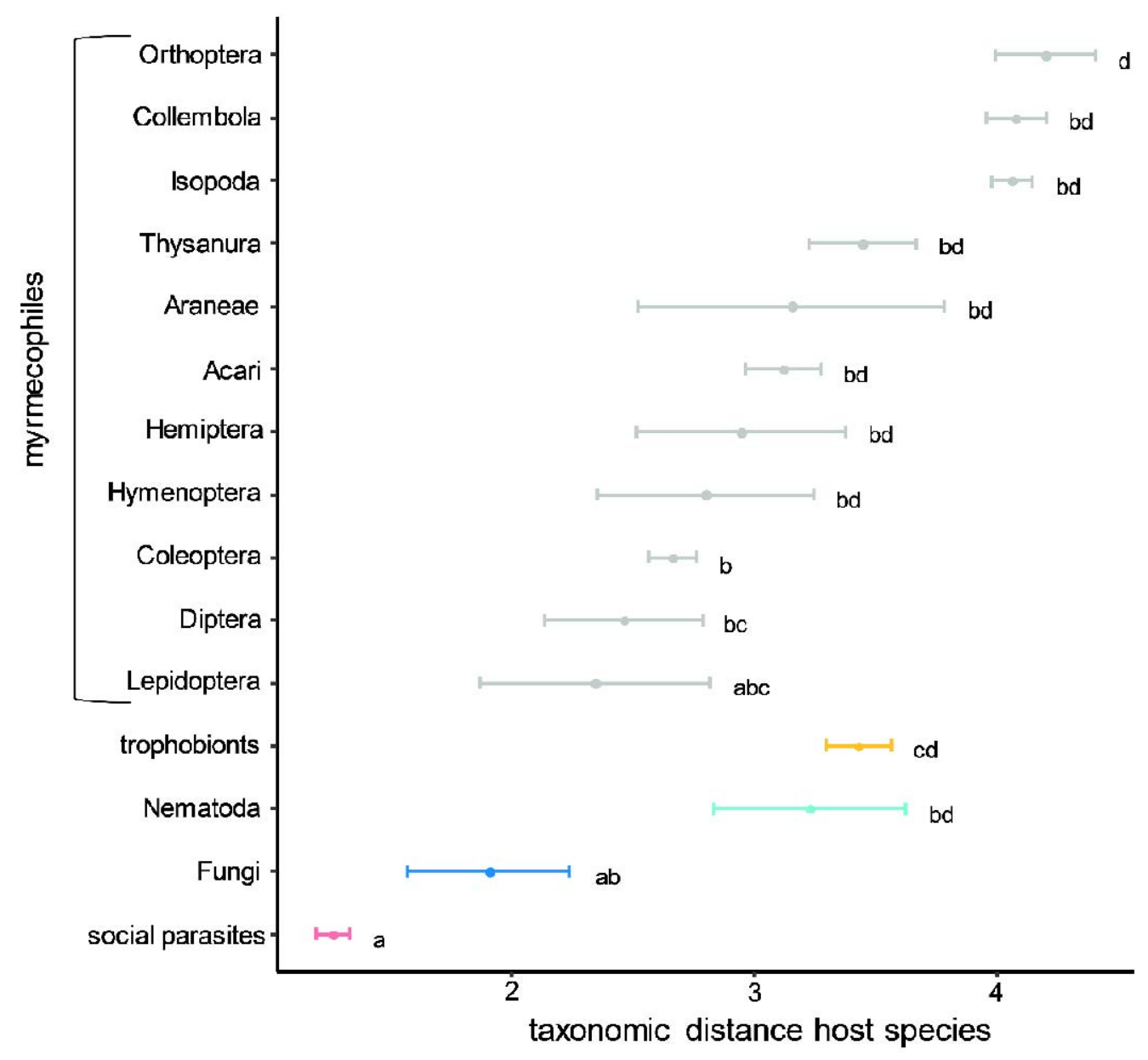

1104 Fig. 4 


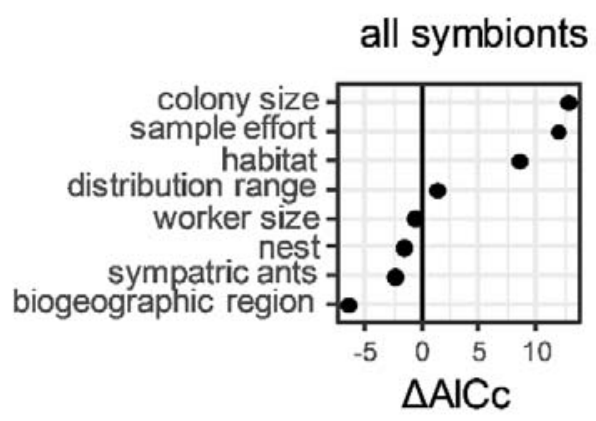

trophobionts

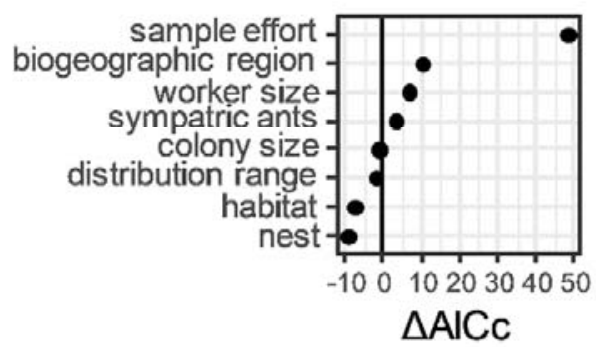

social parasites

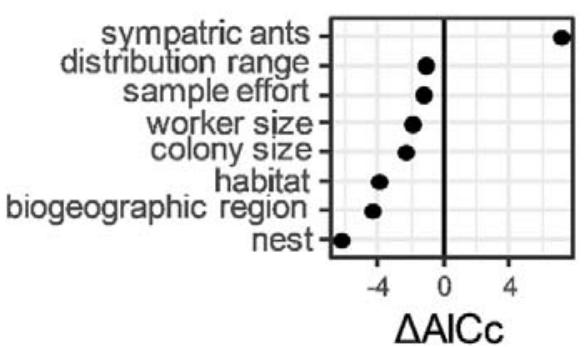

all myrmecophiles

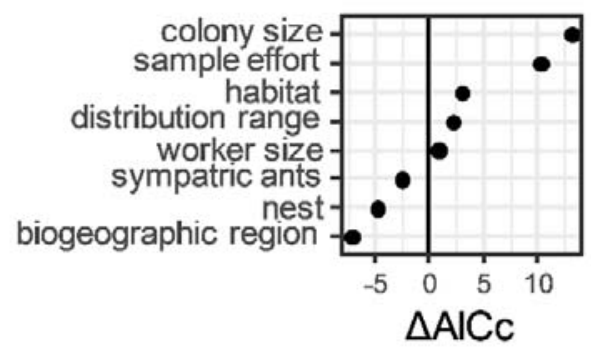

myrmecophilous beetles
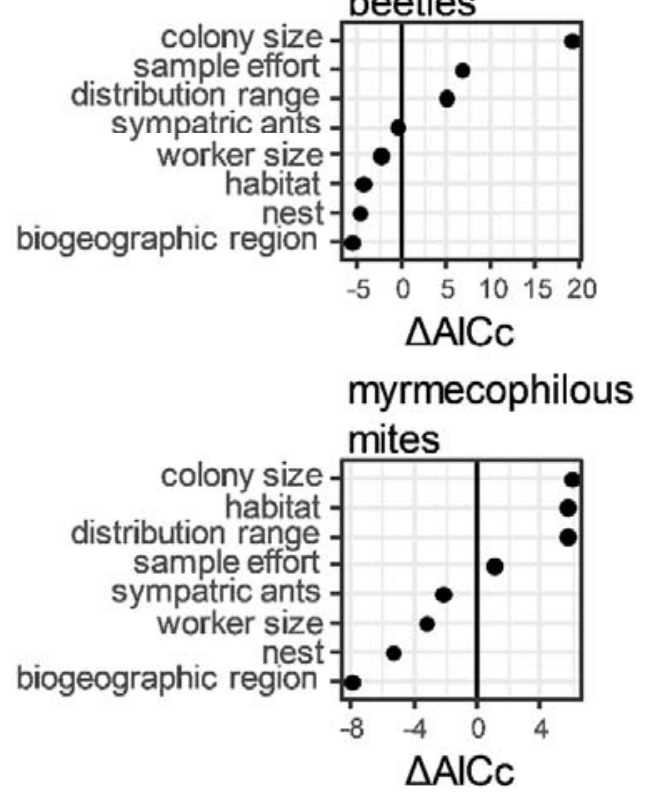

Fig. 5 

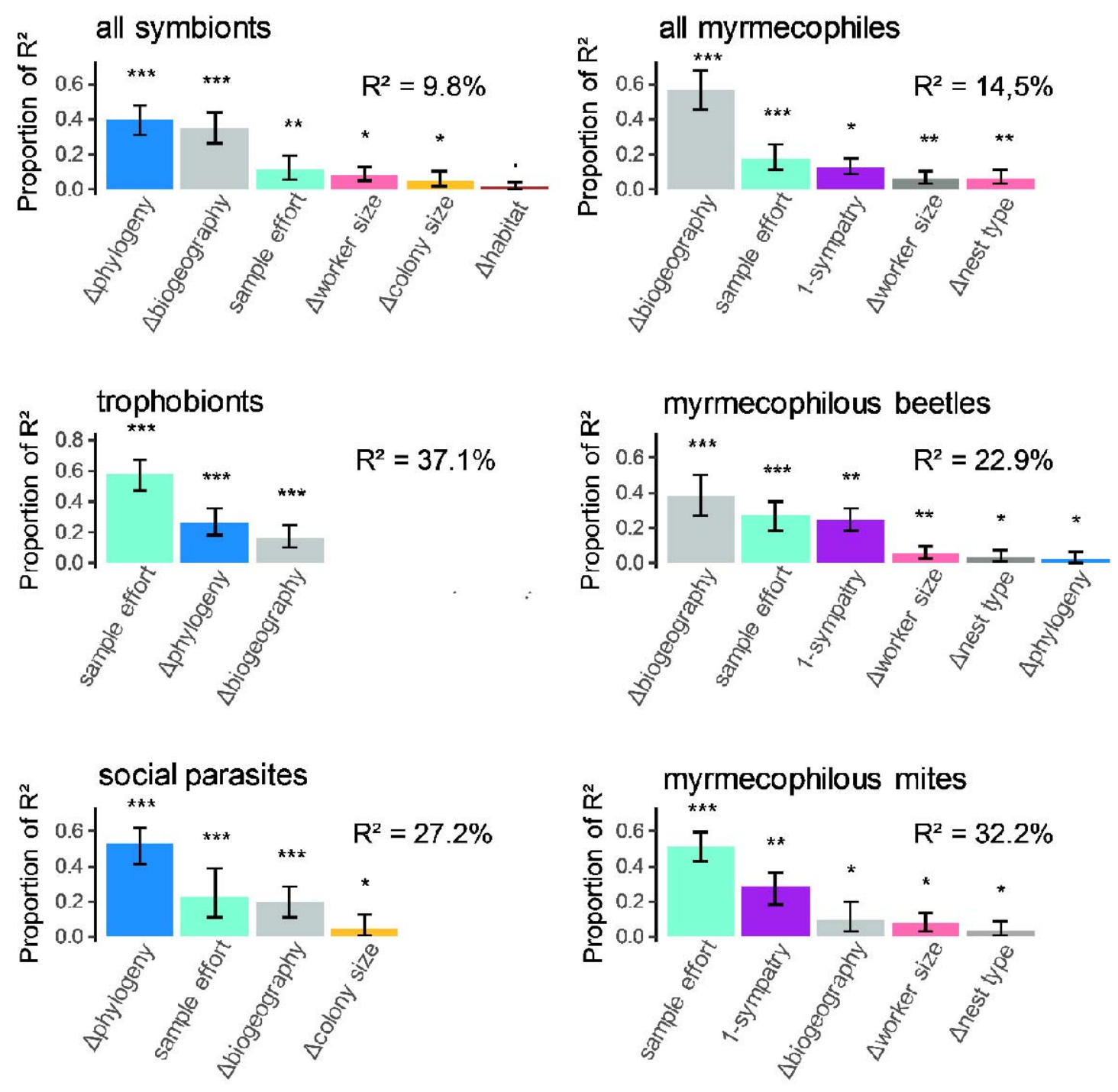

Fig. 6 


\section{TABLES}

1114

1115 Table 1. Estimates for the predictors of the top-ranked PGLS-analyses ( $\triangle \mathrm{AICc}<2)$. The 1116 subset of best models is given for the analyses with total number of (1) symbionts, (2) 1117 myrmecophiles, (3) myrmecophilous beetles, (4) myrmecophilous mites, (5) trophobionts and 1118 (6) social parasites as dependent variable. Significant estimates indicated in bold $(P<0.001$ : $1119{ }^{* * *}, \mathrm{P}<0.01$ : $\left.^{*}, \mathrm{P}<0.05:^{*}, \mathrm{P}<0.10:{ }^{*}\right)$.

\begin{tabular}{|c|c|c|c|c|c|c|c|c|c|c|c|c|c|}
\hline & (Intercept) & $\begin{array}{l}\text { colony } \\
\text { size }\end{array}$ & $\begin{array}{c}\text { sample } \\
\text { effort }\end{array}$ & $\begin{array}{l}\text { biogeo } \\
\text { graphy }\end{array}$ & distribution & habitat & $\begin{array}{l}\text { sympatric } \\
\text { ants }\end{array}$ & $\begin{array}{l}\text { nest } \\
\text { type }\end{array}$ & $\begin{array}{l}\text { worker } \\
\text { size }\end{array}$ & df & $\mathrm{AICc}$ & weight & lambda \\
\hline \multicolumn{14}{|l|}{ all symbionts } \\
\hline & 2.41 & $0.25^{\star \star \star}$ & $0.25^{\star \star \star}$ & & $0.11^{* * *}$ & $t^{\star \star \star}$ & & & & 7 & 88.7 & 0.37 & 0 \\
\hline & 2.46 & $0.24^{\star \star \star}$ & $0.23^{\star \star \star}$ & & $0.13^{\star \star \star}$ & $t^{\star \star \star}$ & & & 0.05 & 8 & 89.2 & 0.28 & 0 \\
\hline & 2.40 & $0.24^{\star \star \star}$ & $0.34^{\star \star \star}$ & & & $+^{\star \star \star}$ & & & & 6 & 90.0 & 0.19 & 0 \\
\hline & 2.51 & $0.22^{\star \star \star}$ & $0.23^{\star \star \star}$ & & $0.14^{\star \star \star}$ & $+^{\star \star \star}$ & & + & & 10 & 90.2 & 0.17 & 0 \\
\hline \multicolumn{14}{|l|}{ myrmecophiles } \\
\hline & 2.27 & $0.21^{\star \star \star}$ & $0.24^{\star \star \star}$ & & $0.13^{\star \star \star}$ & $t^{\star \star \star}$ & & & $0.08=$ & 8 & 69.2 & 0.33 & 0 \\
\hline & 2.20 & $0.21^{\star \star *}$ & $0.26^{\star \star \star}$ & & $0.10^{\star \star \star}$ & $t^{\star \star \star}$ & & & & 7 & 70.0 & 0.21 & 0 \\
\hline & 1.76 & $0.20^{\star \star \star}$ & $0.38^{\star \star \star}$ & & & & & & & 3 & 70.6 & 0.16 & 0 \\
\hline & 2.20 & $0.20^{\star \star \star}$ & $0.33^{\star \star \star}$ & & & $+^{\star \star \star}$ & & & & 6 & 70.6 & 0.16 & 0 \\
\hline & 1.76 & $0.21^{\star \star \star}$ & $0.32^{\star \star \star}$ & & $0.08^{\star \star *}$ & & & & & 4 & 70.9 & 0.14 & 0 \\
\hline \multicolumn{14}{|c|}{$\begin{array}{l}\text { myrmecophilous } \\
\text { beetles }\end{array}$} \\
\hline & 1.53 & $0.22^{\star \star \star}$ & $0.17^{\star \star}$ & & $0.16^{\star \star \star}$ & & & & & 4 & 25.5 & 0.58 & 0 \\
\hline & 1.53 & $0.21^{\star \star *}$ & $0.17^{\star \star}$ & & $0.22^{\star \star \star}$ & & -0.08 & & & 5 & 26.1 & 0.42 & 0 \\
\hline \multicolumn{14}{|c|}{$\begin{array}{l}\text { myrmecophilous } \\
\text { mites }\end{array}$} \\
\hline & 2.00 & $0.14^{\star \star *}$ & $0.13=$ & & $0.15^{\star \star \star}$ & $t^{\star \star \star}$ & & & & 7 & 19.0 & 0.42 & 0 \\
\hline & 1.42 & $0.13^{\star \star \star}$ & $0.25^{\star \star \star}$ & & $0.26^{\star * \star}$ & & $-0.15^{\star}$ & $+^{*}$ & & 8 & 19.5 & 0.34 & 0 \\
\hline & 2.11 & $0.18^{\star \star \star}$ & & & $0.17^{\star \star \star}$ & $+* \star \star$ & & & & 6 & 20.1 & 0.25 & 0 \\
\hline \multicolumn{14}{|l|}{ trophobionts } \\
\hline & 1.70 & & $0.33^{\star \star \star}$ & $t^{\star \star *}$ & & & $-0.08=$ & & $-0.13^{\star *}$ & 8 & -5.2 & 0.36 & 0.35 \\
\hline & 1.71 & & $0.34^{\star \star *}$ & $t^{\star \star *}$ & $-0.12^{\star \star}$ & & & & $-0.15^{\star \star}$ & 8 & -4.8 & 0.30 & 0.42 \\
\hline & 1.61 & $0.05^{\star \star}$ & $0.32^{\star \star \star}$ & $t^{\star \star \star}$ & & & -0.07 & & $-0.14^{\star \star}$ & 9 & -4.0 & 0.20 & 0.30 \\
\hline & 1.70 & & $0.34^{\star \star \star}$ & $t^{\star \star *}$ & $-0.07^{\star *}$ & & -0.05 & & $-0.14^{\star \star}$ & 9 & -3.2 & 0.14 & 0.38 \\
\hline \multicolumn{14}{|l|}{ social parasites } \\
\hline & 1.11 & & & & & & $0.09^{\star \star}$ & & & 2 & -14.25 & 0.25 & 0.79 \\
\hline & 1.14 & & & & $0.10^{\star \star}$ & & & & & 2 & -13.43 & 0.17 & 0.96 \\
\hline & 1.12 & & & & $0.05^{\star \star}$ & & 0.05 & & & 3 & -13.18 & 0.15 & 0.87 \\
\hline & 1.09 & & & & & & $0.08^{\star *}$ & & -0.05 & 3 & -13.15 & 0.15 & 0.74 \\
\hline & 1.10 & & $0.05^{\star \star}$ & & & & 0.06 & & & 3 & -13.05 & 0.14 & 0.86 \\
\hline & 1.09 & & $0.10^{\star \star}$ & & & & & & & 2 & -13.04 & 0.14 & 0.96 \\
\hline
\end{tabular}

